\title{
Mechanism of Rate Acceleration of Radical C-C Bond Formation Reaction by a Radical SAM GTP 3',8-Cyclase
}

\author{
Haoran Pang ${ }^{1}$, Edward A. Lilla ${ }^{1}$, Pan Zhang ${ }^{2}$, Du Zhang ${ }^{2}$, Thomas P. Shields ${ }^{3}$, Lincoln G. Scott ${ }^{3}$, \\ Weitao Yang $^{2}$ and Kenichi Yokoyama ${ }^{1,2, *}$
}

${ }^{1}$ Department of Biochemistry, Duke University School of Medicine, Durham, North Carolina 27710, USA.

2 Department of Chemistry, Duke University, Durham, North Carolina 27710, USA.

${ }^{3}$ Cassia, LLC, 3030 Bunker Hill Street, Suite 214, San Diego, California 92109, United States.

*Corresponding Author: ken.yoko@duke.edu 


\section{Table of Contents}

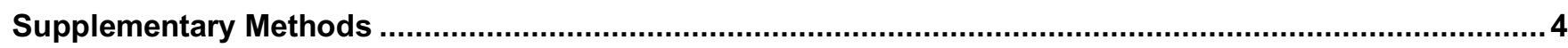

Expression, purification and reconstitution of wt-MoaA ..................................................................

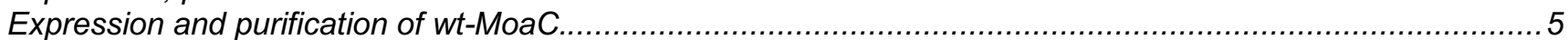

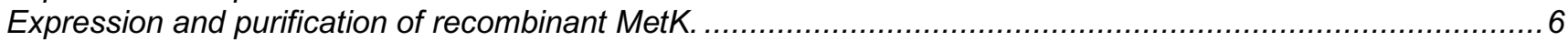

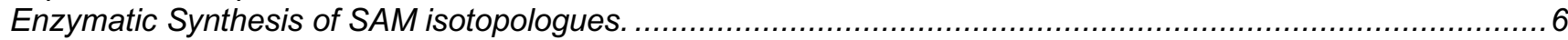

Table S1. The simulated $g$ values and ratio of the two axial signals from the reduced [4Fe-4S] clusters. ${ }^{a} .8$

Table S2. The $g$ values and hyperfine tensors of all the simulated spectra of 5 '-dA-C4'

Table S3. Reported rate constants and activation energies for intramolecular radical cyclization reactions

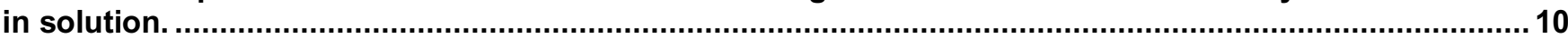

Table S4. DFT calculation of 3',8-cyclization reaction in eight different systems. ................................11

Table S5. Geometric structures from 4 systems not shown in main contents ........................................12

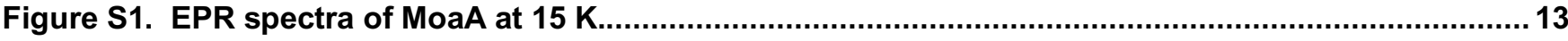

Figure S2. EPR characterization of MoaA [4Fe-4S] clusters in three different buffers at $15 \mathrm{~K} . \ldots \ldots \ldots \ldots . . . . . . .14$

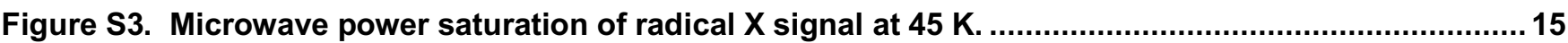

Figure S4. Microwave power saturation of the C-7' radical observed in C209A-PolH measured at 77 K. .. 16

Figure S5. ${ }^{1} \mathrm{H}$ NMR $(700 \mathrm{MHz})$ of (4'S)-5'-dA isolated from MoaA reaction. ........................................... 17

Figure S6. ${ }^{1} \mathrm{H}-{ }^{1} \mathrm{H}$ COSY $\left(700 \mathrm{MHz}, \mathrm{D}_{2} \mathrm{O}, 313 \mathrm{~K}\right)$ of $\left(4^{\prime} \mathrm{S}\right)-5$ '-dA isolated from MoaA reaction........................ 18

Figure S7. ${ }^{1} \mathrm{H}$ NMR $(700 \mathrm{MHz})$ of (4' $R$ )-5'-dA isolated from MoaA reaction. .............................................19

Figure S8. ${ }^{1} \mathrm{H}-{ }^{1} \mathrm{H}$ COSY $\left(700 \mathrm{MHz}, \mathrm{D}_{2} \mathrm{O}, 313 \mathrm{~K}\right)$ of $\left(4^{\prime} \mathrm{R}\right)-5^{\prime}-\mathrm{dA}$ isolated from MoaA reaction.........................20

Figure S9. LCMS of (4'R)- and (4'S)-5'-dA formed in MoaA assay with [3'-2 H]GTP (A) or in ${ }^{2} \mathrm{H}_{2} \mathrm{O}(\mathrm{B})$. ........ 21

Figure S10. MoaA activity with non-labeled or isotopically labeled SAM. ............................................22

Figure S11. Overlay of EPR spectra of MoaA reaction with GTP and SAM or [4'-2 H]SAM........................23

Figure S12. Formations of (4'S)-5'-dA in MoaA assays with non-labeled or isotopically labeled SAM. ..... 24

Figure S13. EPR spectrum of $18.0 \mu \mathrm{M}$ flavosemiquinone radical at $45 \mathrm{~K}$..............................................25

Figure S14. Comparison of the radical signals in MoaA assay (black) and MoaA/MoaC coupled assay

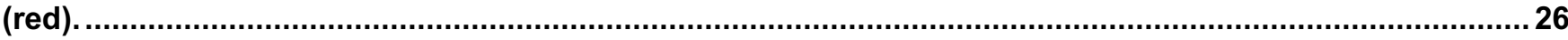

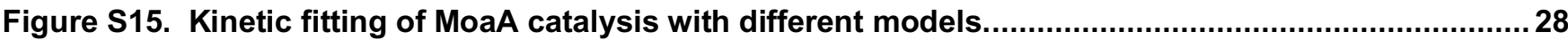

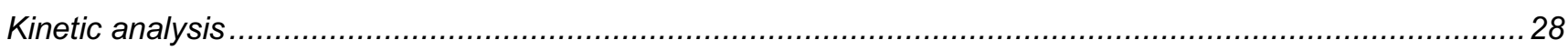

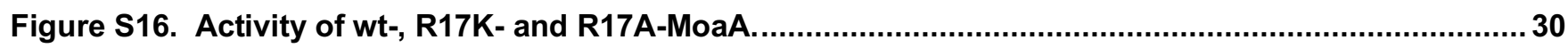

Figure S17. Overlay of EPR spectra of wt-MoaA and R17K-MoaA complete reactions............................. 31

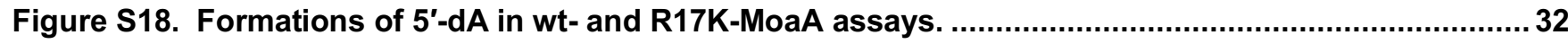

Figure S19. MS of enzymatically prepared non-labeled SAM.

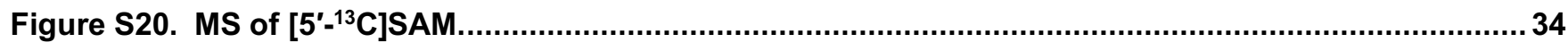

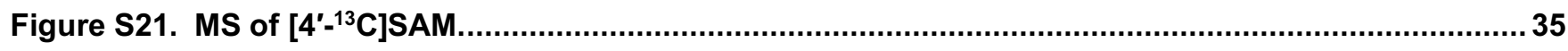

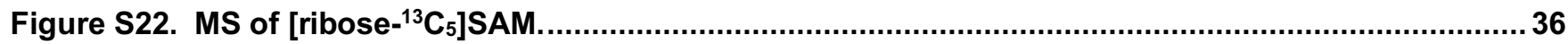

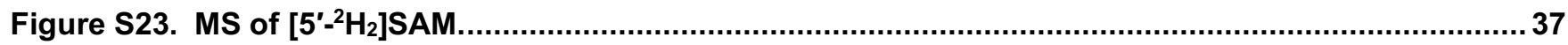

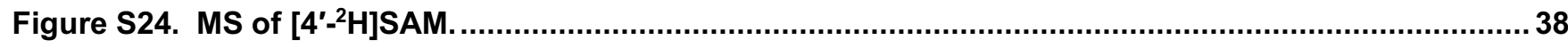

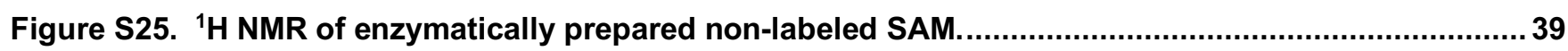

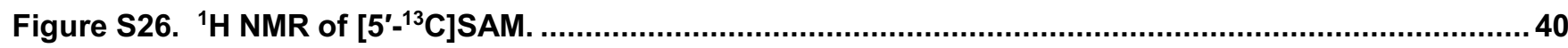

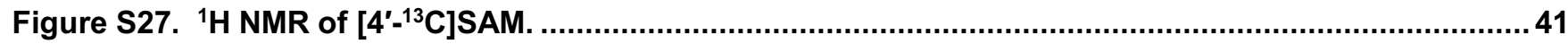




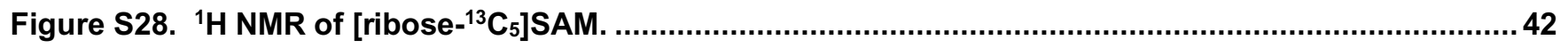

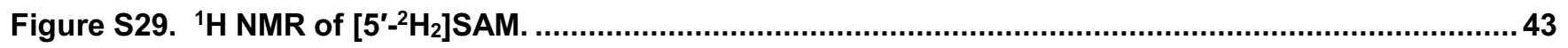

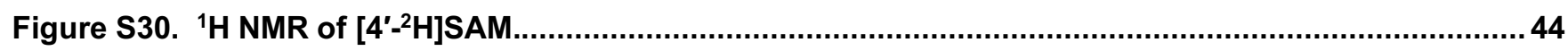

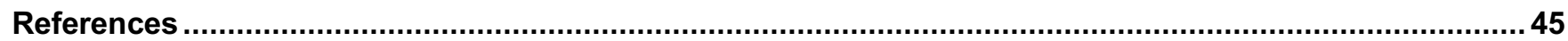




\section{Supplementary Methods}

Expression, purification and reconstitution of wt-MoaA.

Staphylococcus aureus MoaA with a hexahistidine ( $\left.\mathrm{His}_{6}\right)$ tag at the $\mathrm{N}$-terminus was heterologously expressed in E. coli BL21(DE3) harboring pET15b-wtMoaA and a plasmid for the expression of SUF proteins responsible for [4Fe-4S] cluster biosynthesis ${ }^{1}$ (kindly provided by $\mathrm{Dr}$. Hänzelmann Schindelin). All cultures were carried out in the presence of chloramphenicol (35 mg/L) and Ampicillin (100 mg/L). A single colony was picked and grown in LB medium $(5 \mathrm{~mL})$ for $8 \mathrm{hrs}$, which was diluted into $250 \mathrm{~mL}$ LB in a $500 \mathrm{~mL}$ baffled flask incubated at $37^{\circ} \mathrm{C}$ with rigorous shaking until the growth reaches saturation $(16 \mathrm{hrs})$. A portion $(40 \mathrm{~mL})$ of this culture was used to inoculate $1.5 \mathrm{~L}$ of LB medium in a $2.8 \mathrm{~L}$ baffled flask, which was incubated at $37^{\circ} \mathrm{C}$ with rigorous shaking at $200 \mathrm{rpm}$ until the $\mathrm{OD}_{600}$ reaches $0.9 \sim 1.0$. Then the temperature was lowered to $30^{\circ} \mathrm{C}$ and MoaA expression was induced by an addition of $0.5 \mathrm{mM}$ IPTG. The culture was continued for an additional $4 \mathrm{hrs}$. The cells were harvested by centrifugation, frozen in liquid nitrogen, and stored at $-80{ }^{\circ} \mathrm{C}$. Typically, $3 \sim 4 \mathrm{~g}$ of wet cell pellet/L of culture was obtained.

All purification and reconstitution procedures were carried out anaerobically in $\mathrm{mBraun}$ glovebox ( $<0.1 \mathrm{ppm} \mathrm{O}_{2}, 10{ }^{\circ} \mathrm{C}$ ). The cell pellet was transferred into the glovebox and resuspended and homogenized in 4 volumes of buffer $A(50 \mathrm{mM}$ Tris $\cdot \mathrm{HCl}, \mathrm{pH} 7.6,0.3 \mathrm{M} \mathrm{NaCl}$ and $10 \%$ glycerol) supplemented with $3 \mathrm{mM} \beta$-mercaptoethanol ( $\beta \mathrm{ME})$. The cells were lysed by two passages through a French press cell (> 14000 psi) with the protection of argon. Cellular debris was removed by centrifugation at $25,000 \times g$ and $4{ }^{\circ} \mathrm{C}$ for $30 \mathrm{~min}$. The supernatant was loaded onto $20 \mathrm{~mL} \mathrm{Ni-NTA}$ agarose resin (Qiagen) equilibrated in buffer A supplemented with $3 \mathrm{mM} \beta \mathrm{ME}$ and $20 \mathrm{mM}$ imidazole. Then the resin was washed with buffer $A$ supplemented with $3 \mathrm{mM} \beta M E$ and $20 \mathrm{mM}$ imidazole for 20 column volumes. MoaA was then eluted using buffer A supplemented with $3 \mathrm{mM} \beta M E$ and $250 \mathrm{mM}$ imidazole. The fractions containing MoaA as judged by Bradford reagent were combined and desalted using a Sephadex G-25 column equilibrated with buffer A supplemented with $5 \mathrm{mM}$ DTT. The concentration of this as-isolated MoaA was quantified by Bradford assay using an apo-wt-MoaA protein as standard. The apo-MoaA was prepared by incubating as-isolated MoaA with $10 \mathrm{mM}$ EDTA and $6 \mathrm{M}$ guanidine $\mathrm{HCl}$ to remove [4Fe-4S] cluster. The denatured protein was desalted by $\mathrm{G}-25$ column equilibrated in buffer $\mathrm{A}$ supplemented with $5 \mathrm{mM}$ DTT. Any precipitation was removed by centrifugation at $16,100 \times \mathrm{g}$ and $4{ }^{\circ} \mathrm{C}$ for $10 \mathrm{~min}$. Apo-MoaA concentration was determined based on UV absorption at $280 \mathrm{~nm}$ using the extinction coefficients $\left(\varepsilon_{280 \mathrm{~nm}}=26.2 \mathrm{mM}^{-1} \cdot \mathrm{cm}^{-1}\right)$ as determined by Edelhoch's method. The amount of Fe co-purified with as-isolated MoaA was quantified by Ferrozine assay. Typically, $8 \sim 10 \mathrm{mg}$ as-isolated MoaA/g cell paste was obtained, with $2.5 \pm 0.17$ eq. of Fe per monomer co-purified.

Reconstitution of the [4Fe-4S] cluster was performed using as-isolated MoaA. To the MoaA solution (diluted to $\sim 200 \mu \mathrm{M}$ ), an additional portion of $\left(\mathrm{NH}_{4}\right)_{2} \mathrm{Fe}^{\prime \prime}\left(\mathrm{SO}_{4}\right)_{2}$ and $\mathrm{Na}_{2} \mathrm{~S}$ was added to reach 9 eq. of $\mathrm{Fe}^{2+}$ and $\mathrm{S}^{2-}$ per monomer in total (including co-purified $\mathrm{Fe}$ ). $25 \mathrm{mM}$ stock solution of $\left(\mathrm{NH}_{4}\right)_{2} \mathrm{Fe}^{\prime \prime}\left(\mathrm{SO}_{4}\right)_{2}$ and $\mathrm{Na}_{2} \mathrm{~S}$ was added dropwisely in 10 cycles over the time course of $30 \mathrm{~min}$. The 
enzyme was incubated for another $45 \mathrm{~min}$ and then buffer exchanged into buffer A supplemented with 5 mM DTT by Sephadex G25 column chromatography. The resulting protein was concentrated to $0.5 \sim$ $0.7 \mathrm{mM}$ and then flash frozen in liquid nitrogen and stored at $-80^{\circ} \mathrm{C}$. The concentration and amount of Fe were quantified using same protocol as as-isolated MoaA. This reconstitution yielded MoaA with 5.8 \pm 0.59 eq. of Fe per monomer (1.45 \pm 0.15 eq. reconstituted [4Fe-4S] per monomer). The $k_{\text {cat }}$ values of the reconstituted wt-MoaA were determined to be $0.097 \pm 0.018 \mathrm{~min}^{-1}$ from 4 independent preparation of MoaA.

Staphylococcus aureus MoaA variants (R17K, R17A) were prepared by following the Stratagene QuickChange site-directed mutagenesis protocol by using the pET15b-wtMoaA as a template and the following primers:

\section{R17K: f-GACGTCCCATCCGTGACTTAAAATTATCTGTGACAGATCGG r-CCGATCTGTCACAGATAATTTTAAGTCACGGATGGGACGTC \\ R17A: f-GACGTCCCATCCGTGACTTAGCGTTATCTGTGACAGATC r-GATCTGTCACAGATAACGCTAAGTCACGGATGGGACGTC}

MoaA variants were expressed, purified, reconstituted and assayed in the manner identical to wt-MoaA.

Expression and purification of wt-MoaC.

E. coli wt-MoaC with a hexahistidine $\left(\mathrm{His}_{6}\right)$ tag at the $\mathrm{N}$-terminus was expressed in $E$. coli BL21(DE3) harboring pET30b-wtMoaC. All cultures were carried out in the presence of kanamycin (50 $\mathrm{mg} / \mathrm{L})$. A single colony was picked and grown in LB medium $(5 \mathrm{~mL})$ for $8 \mathrm{hrs}$, which was diluted into 250 $\mathrm{mL}$ LB in a $500 \mathrm{~mL}$ baffled flask incubated at $37^{\circ} \mathrm{C}$ with rigorous shaking until the growth reaches saturation $(16 \mathrm{hrs})$. A portion $(40 \mathrm{~mL})$ of this culture was used to inoculate $1.5 \mathrm{~L}$ of LB medium in a $2.8 \mathrm{~L}$ baffled flask, which was incubated at $37^{\circ} \mathrm{C}$ with rigorous shaking at $200 \mathrm{rpm}$ until the $\mathrm{OD}_{600}$ reaches 0.9 1.0. Then MoaC expression was induced by an addition of $0.5 \mathrm{mM}$ IPTG. The culture was continued for an additional $4 \mathrm{hrs}$ at $37^{\circ} \mathrm{C}$. The cells were harvested by centrifugation, frozen in liquid nitrogen, and stored at $-80{ }^{\circ} \mathrm{C}$. Typically, $4 \sim 5 \mathrm{~g}$ of wet cell pellet/L of culture was obtained.

E. coli MoaC purification was carried out aerobically under $4{ }^{\circ} \mathrm{C}$. The cell pellet was resuspended and homogenized in 4 volumes of buffer $\mathrm{A}(50 \mathrm{mM}$ Tris $\bullet \mathrm{HCl}, \mathrm{pH} 7.6,0.3 \mathrm{M} \mathrm{NaCl}$ and $10 \%$ glycerol) supplemented with $3 \mathrm{mM} \beta \mathrm{ME}$. The cells were lysed by two passages through a French press cell (> $14000 \mathrm{psi}$ ) and centrifuged at $25,000 \times \mathrm{g}$ and $4{ }^{\circ} \mathrm{C}$ for $30 \mathrm{~min}$. The supernatant was loaded onto $20 \mathrm{~mL}$ Ni-NTA agarose resin (Qiagen) equilibrated in buffer A supplemented with $3 \mathrm{mM} \beta \mathrm{ME}$ and $20 \mathrm{mM}$ imidazole. Then the resin was washed with buffer A supplemented with $3 \mathrm{mM} \beta M E$ and $20 \mathrm{mM}$ imidazole for 20 column volumes. MoaC was then eluted using buffer A supplemented with $3 \mathrm{mM} \beta \mathrm{ME}$ and 250 $\mathrm{mM}$ imidazole. The fractions containing $\mathrm{MoaC}$ as judged by Bradford reagent were combined and desalted using a Sephadex G-25 column equilibrated with buffer A supplemented with 5 mM DTT. Protein concentration was determined based on UV absorption at $280 \mathrm{~nm}$ using the extinction coefficients $\left(\varepsilon_{280 \mathrm{~nm}}\right.$ $=7.37 \mathrm{mM}^{-1} \mathrm{~cm}^{-1}$ ) as determined by Edelhoch's method. Typically, $10 \sim 12 \mathrm{mg}$ MoaC/g cell paste was 
obtained. MoaC was then degassed on a Schlenk line using 4 cycles of $30 \mathrm{~s}$ evacuation followed by 5 min of argon gas refill and transferred into glovebox for anaerobic assays. The degassed protein was then fast-frozen and stored at $-80{ }^{\circ} \mathrm{C}$.

\section{Expression and purification of recombinant MetK.}

The plasmids for expression of E.coli SAM synthetase (MetK) was kindly provided by Dr. Dewey McCafferty at Duke University. MetK was heterologously expressed in E. coli BL21(DE3) cells harboring pET30b-MetK and a pLacl plasmid containing GroEL, GroES chaperon proteins from S. lividans ${ }^{2-4}$. All culture media contained kanamycin (35 mg/L) and chloramphenicol (25 mg/L). A single colony was picked and grown in LB medium (5 mL) for $8 \mathrm{hrs}$ followed by dilution into $250 \mathrm{~mL}$ LB in a $500 \mathrm{~mL}$ baffled flask incubated at $37^{\circ} \mathrm{C}$ until the growth reaches saturation (16 hrs). A portion $(40 \mathrm{~mL})$ of this culture was used to inoculate $1.5 \mathrm{~L}$ of LB medium in a $2.8 \mathrm{~L}$ baffled flask and grown at $37^{\circ} \mathrm{C}$ until the $\mathrm{OD}_{600}$ reaches $0.6 \sim 0.8$. MetK expression was induced by an addition of $0.25 \mathrm{mM}$ IPTG. The culture was continued for an additional $4 \mathrm{hrs}$. The cells were harvested by centrifugation, frozen in liquid nitrogen, and stored at $-80{ }^{\circ} \mathrm{C}$. Typically, $5 \sim 6 \mathrm{~g}$ of wet cell pellet/L of culture were obtained.

MetK was aerobically purified. The cell pellets were resuspended and homogenized in four volumes of buffer $\mathrm{A}(50 \mathrm{mM}$ Tris $\mathrm{HCl}, \mathrm{pH} 7.6,0.3 \mathrm{M} \mathrm{NaCl}$ and $10 \%$ glycerol) supplemented with $3 \mathrm{mM}$ $\beta \mathrm{ME}$. The cells were lysed by two passages through a French pressure cell operating at 14,000 psi. The resulting lysate was cleared by centrifugation at $25,000 \times g$ and $4{ }^{\circ} \mathrm{C}$ for $30 \mathrm{~min}$. The supernatant was loaded onto $20 \mathrm{~mL}$ Ni-NTA agarose resin equilibrated in buffer A supplemented with $3 \mathrm{mM} \beta \mathrm{ME}$ and 20 $\mathrm{mM}$ imidazole. Then the resin was washed with buffer $\mathrm{A}$ supplemented with $3 \mathrm{mM} \beta \mathrm{ME}$ and $20 \mathrm{mM}$ imidazole for 20 column volumes. MetK was then eluted using buffer A supplemented with $3 \mathrm{mM} \beta \mathrm{ME}$ and $250 \mathrm{mM}$ imidazole. Fractions containing MetK, determined by SDS-PAGE, were exchanged into buffer $\mathrm{C}\left(50 \mathrm{mM}\right.$ Tris $\mathrm{HCl} \mathrm{pH} 8.0,100 \mathrm{mM} \mathrm{KCl}, 10 \mathrm{mM} \mathrm{MgCl}_{2}$, and 10\% glycerol) using a Sephadex G25 column. The concentration of MetK was determined based on the UV absorption at $280 \mathrm{~nm}$ using the extinction coefficients $\left(\varepsilon_{280 \mathrm{~nm}}=40.1 \mathrm{mM}^{-1} \mathrm{~cm}^{-1}\right)$ determined by Edelhoch's method.

\section{Enzymatic Synthesis of SAM isotopologues.}

All natural isotope abundant and the isotopically enriched SAM ([ribose- $\left.{ }^{13} \mathrm{C}_{5}\right] \mathrm{SAM},\left[5^{\prime}-{ }^{13} \mathrm{C}\right] \mathrm{SAM}$, $\left[5^{\prime}-{ }^{2} \mathrm{H}_{2}\right]$ SAM, $\left[4^{\prime}-{ }^{13} \mathrm{C}\right] \mathrm{SAM}$, and $\left.\left[4^{\prime}-{ }^{2} \mathrm{H}\right] \mathrm{SAM}\right]$ ) were prepared from (isotopically labeled) ATP and L-Met. The isotopically labeled ATP was enzymatically synthesized from isotopically labeled D-ribose or Dglucose using de novo purine biosynthesis enzymes ${ }^{5-6}$. To enzymatically generate SAM from ATP and L-Met, $30 \mathrm{~mL}$ reaction containing $10 \mathrm{mM}$ isotope labeled ATP, $15 \mathrm{mM} \mathrm{L-Met,} 100 \mathrm{mM} \mathrm{Tris} \mathrm{HCl} \mathrm{(pH} \mathrm{8.0),}$ $50 \mathrm{mM} \mathrm{KCl}, 30 \mathrm{mM} \mathrm{MgCl}$, $8 \% \mathrm{v} / \mathrm{v} \beta \mathrm{ME}$ and $3 \mathrm{mg} / \mathrm{mL}$ MetK was incubated at room temperature and reaction progress was monitored by HPLC. The reaction typically yielded approximately $60 \%$ conversion (based on the starting concentration of ATP) after $4 \mathrm{~h}$ incubation. The reaction was quenched by adjusting the $\mathrm{pH}$ to 5 by adding $\mathrm{HCl}$. 
Purification of SAM was based on the previous report ${ }^{3}$. The quenched reaction mixture was centrifuged, and the supernatant was then loaded onto $100 \mathrm{~mL}$ of weak cation exchange resin (Amberlite CG-50) equilibrated with $1 \mathrm{mM}$ sodium acetate $(\mathrm{pH} 5)$ buffer. The column was washed with the same buffer for 5 column volumes (CV) and then SAM was eluted using $40 \mathrm{mM} \mathrm{H}_{2} \mathrm{SO}_{4}$. Fractions containing SAM determined by UV and HPLC were pooled and titrated with QAE Sephadex A-25 resin in hydroxide form to $\mathrm{pH}$ 5. The resultant solution was then concentrated by rotary evaporation to less than $3 \mathrm{~mL}$, and loaded onto a $150 \mathrm{~mL}$ Bio-Rad Biogel-P2 size exclusion column equilibrated in $\mathrm{H}_{2} \mathrm{O}$. SAM was eluted with $\mathrm{H}_{2} \mathrm{O}$ after $2 \mathrm{CV}$. Fractions containing SAM determined by UV and HPLC were pooled and concentrated by rotary evaporation to less than $3 \mathrm{~mL}$. This solution was degassed and transferred into glovebox for anaerobic assays. The compounds were characterized by MS and NMR and stored at $35^{\circ} \mathrm{C}$ in the glovebox. This method generally yields SAM with >96\% purity (analyzed by HPLC) and a total yield of $\sim 25 \%$ based on ATP. 
Table S1. The simulated $g$ values and ratio of the two axial signals from the reduced [4Fe-4S] clusters. $^{a}$

\begin{tabular}{|c|c|c|c|c|c|c|c|}
\hline \multirow{2}{*}{ substrate } & \multicolumn{2}{|c|}{ species 1} & \multicolumn{2}{|c|}{ species 2} & \multirow{2}{*}{ species $1(\%)$} & \multirow{2}{*}{ species 1:2 } & \multirow{2}{*}{$\begin{array}{l}\text { total }[4 \mathrm{Fe}-4 S]^{+} \\
(\text {eq. of MoaA })^{b}\end{array}$} \\
\hline & $g \perp$ & $g / /$ & $g \perp$ & $g / /$ & & & \\
\hline- & 1.897 & 2.031 & 1.875 & 2.063 & $57.4 \pm 1.5$ & $1.35 \pm 0.08$ & $0.94 \pm 0.09$ \\
\hline SAM & 1.897 & 2.031 & 1.875 & 2.063 & $56.0 \pm 1.5$ & $1.28 \pm 0.08$ & $0.94 \pm 0.07$ \\
\hline GTP & 1.890 & 2.029 & 1.881 & 2.063 & $23.1 \pm 1.0$ & $0.30 \pm 0.02$ & $1.11 \pm 0.06$ \\
\hline GTP+SAM & 1.890 & 2.029 & 1.881 & 2.063 & $24.1 \pm 1.2$ & $0.32 \pm 0.02$ & $1.07 \pm 0.01$ \\
\hline
\end{tabular}

a Values are averages of three replicates and the errors represent standard deviation. ${ }^{\mathrm{b}}$ Total amounts of reduced [4Fe-4S] clusters are quantified by EPR based on $1 \mathrm{mM} \mathrm{Cu}$ standard. 
Table S2. The $g$ values and hyperfine tensors of all the simulated spectra of $5^{\prime}-\mathrm{dA}-\mathrm{C} 4^{\prime} \cdot$.

\begin{tabular}{|c|c|c|c|c|c|c|c|c|c|c|c|c|c|c|c|c|}
\hline Radical & SAM & $g_{\mathrm{xx}}$ & $g_{\mathrm{yy}}$ & $g_{\mathrm{zz}}$ & $A 1_{x x}$ & $\mathrm{~A} 1_{\mathrm{yy}}$ & $\mathrm{A} 1_{\mathrm{zz}}$ & $A 2_{x x}$ & $\mathrm{~A} 2_{\mathrm{yy}}$ & $\mathrm{A} 2_{\mathrm{zz}}$ & $A 3_{x x}$ & $\mathrm{~A} 3_{\mathrm{yy}}$ & $\mathrm{A} 3_{\mathrm{zz}}$ & $\mathrm{A} 4_{\mathrm{xx}}$ & $\mathrm{A} 4_{\mathrm{yy}}$ & $\mathrm{A} 4_{\mathrm{zz}}$ \\
\hline \multirow{5}{*}{$x$} & SAM & 2.0059 & 2.0068 & 2.0092 & 72.1 & 66.6 & 57.6 & 43.7 & 66.1 & 113.6 & 64.1 & 21.3 & 111.3 & - & - & - \\
\hline & {$\left[5^{\prime}-{ }^{13} \mathrm{C}\right] \mathrm{SAM}$} & 2.0059 & 2.0068 & 2.0092 & 72.1 & 66.6 & 57.6 & 43.7 & 66.1 & 113.6 & 64.1 & 21.3 & 111.3 & 19.4 & 28.0 & 31.2 \\
\hline & {$\left[5^{\prime}-D_{2}\right]$ SAM } & 2.0059 & 2.0068 & 2.0092 & 72.1 & 66.6 & 57.6 & 6.7 & 10.2 & 17.5 & 9.9 & 3.3 & 17.1 & - & - & - \\
\hline & {$\left[4^{\prime}-{ }^{13} \mathrm{C}\right] \mathrm{SAM}$} & 2.0059 & 2.0068 & 2.0092 & 72.1 & 66.6 & 57.6 & 43.7 & 66.1 & 113.6 & 64.1 & 21.3 & 111.3 & 42.1 & 215.3 & 202.4 \\
\hline & [ribose- ${ }^{13} \mathrm{C}_{5}$ ]SAM & 2.0059 & 2.0068 & 2.0092 & 72.1 & 66.6 & 57.6 & 43.7 & 66.1 & 113.6 & 64.1 & 21.3 & 111.3 & 42.1 & 215.3 & 202.4 \\
\hline \multirow{5}{*}{$\mathrm{Y}$} & SAM & 2.0059 & 2.0068 & 2.0092 & 11.1 & 10.2 & 8.9 & 43.7 & 66.1 & 113.6 & 64.1 & 21.3 & 111.3 & - & - & - \\
\hline & {$\left[5^{\prime}-{ }^{13} \mathrm{C}\right] \mathrm{SAM}$} & 2.0059 & 2.0068 & 2.0092 & 11.1 & 10.2 & 8.9 & 43.7 & 66.1 & 113.6 & 64.1 & 21.3 & 111.3 & 19.4 & 28.0 & 31.2 \\
\hline & {$\left[5^{\prime}-D_{2}\right]$ SAM } & 2.0059 & 2.0068 & 2.0092 & 11.1 & 10.2 & 8.9 & 6.7 & 10.2 & 17.5 & 9.9 & 3.3 & 17.1 & - & - & - \\
\hline & {$\left[4^{\prime}-{ }^{13} \mathrm{C}\right] \mathrm{SAM}$} & 2.0059 & 2.0068 & 2.0092 & 11.1 & 10.2 & 8.9 & 43.7 & 66.1 & 113.6 & 64.1 & 21.3 & 111.3 & 42.1 & 215.3 & 202.4 \\
\hline & [ribose- ${ }^{13} \mathrm{C}_{5}$ ]SAM & 2.0059 & 2.0068 & 2.0092 & 11.1 & 10.2 & 8.9 & 43.7 & 66.1 & 113.6 & 64.1 & 21.3 & 111.3 & 42.1 & 215. & 202.4 \\
\hline
\end{tabular}


Table S3. Reported rate constants and activation energies for intramolecular radical cyclization reactions in solution.

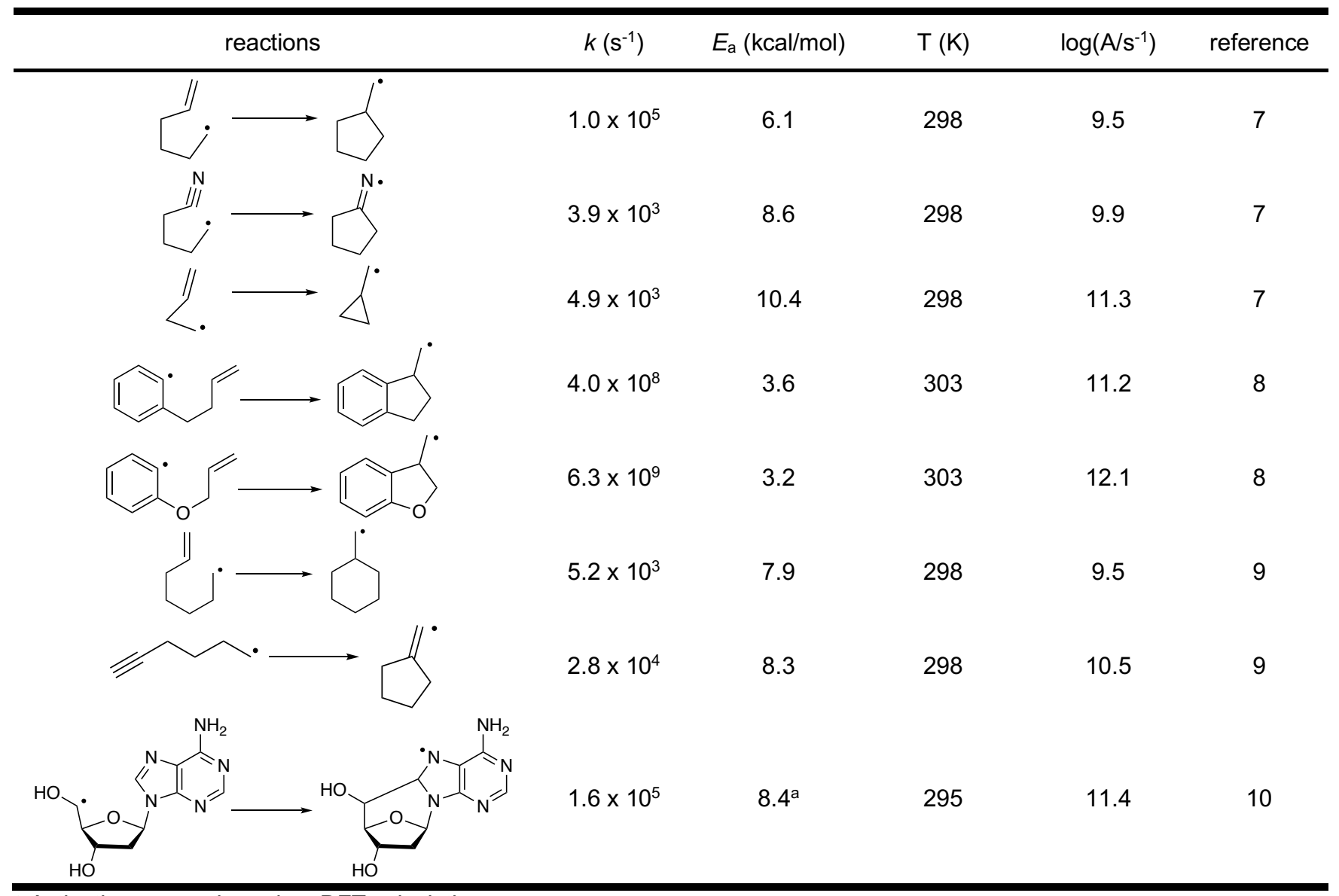

${ }^{a}$ Activation energy based on DFT calculation. 
Table S4. DFT calculation of 3',8-cyclization reaction in eight different systems.

\begin{tabular}{|c|c|c|c|c|c|c|c|c|c|c|c|c|c|c|c|c|}
\hline \multirow{2}{*}{ System } & \multirow{2}{*}{ No. } & \multicolumn{5}{|c|}{ Reactant (GTP-C3'•) } & \multicolumn{5}{|c|}{ Transition state (TS) } & \multicolumn{5}{|c|}{ Product (3',8-cyclo-GTP aminyl radical) } \\
\hline & & $\begin{array}{c}\text { Free } \\
\text { energy }^{a} \\
\end{array}$ & $C 3^{\prime}-C 8^{b}$ & $3^{\prime} \mathrm{OH}-\alpha P^{c}$ & $\begin{array}{l}3{ }^{\prime} \mathrm{OH}- \\
\mathrm{R} / \mathrm{K} 17^{\mathrm{d}} \\
\end{array}$ & $\begin{array}{c}\mathrm{N} 9 \\
\text { planaritye }\end{array}$ & $\begin{array}{c}\begin{array}{c}\text { Free } \\
\text { energy }^{\mathrm{a}}\end{array} \\
\end{array}$ & $C 3^{\prime}-C 8^{b}$ & $3^{\prime} \mathrm{OH}-\alpha \mathrm{P}^{\mathrm{c}}$ & $\begin{array}{l}\text { 3'OH- } \\
\mathrm{R} / \mathrm{K} 17^{\mathrm{d}} \\
\end{array}$ & $\begin{array}{c}\mathrm{N} 9 \\
\text { planaritye } \\
\end{array}$ & $\begin{array}{c}\text { Free } \\
\text { energy }^{a} \\
\end{array}$ & $\mathrm{C} 3^{\prime}-\mathrm{C}^{\mathrm{b}}$ & $3^{\prime} \mathrm{OH}-\alpha \mathrm{P}^{\mathrm{c}}$ & $\begin{array}{l}3^{\prime} \mathrm{OH}- \\
\mathrm{R} / \mathrm{K} 17^{\mathrm{d}} \\
\end{array}$ & $\begin{array}{c}\mathrm{N} 9 \\
\text { planarity } \\
\end{array}$ \\
\hline $\begin{array}{c}\text { GTP-C3'• } \\
\text { (no restraints) }\end{array}$ & 1 & 0.00 & 3.54 & - & - & -176.5 & 24.56 & 2.17 & - & - & 125.2 & 3.66 & 1.55 & - & - & 116.7 \\
\hline $\begin{array}{c}\text { GTP-C3'• } \\
\text { (PPP restraints) }\end{array}$ & $1^{\prime}$ & 0.00 & 3.35 & 1.77 & - & -173.9 & 28.28 & 2.16 & 1.79 & - & 125.2 & -2.75 & 1.54 & 1.63 & - & 115.9 \\
\hline $\begin{array}{c}\text { GTP-C3'• } \\
(\text { PPP + guanine restraints })\end{array}$ & 2 & 0.00 & 3.19 & 1.92 & - & 151.4 & 19.22 & 2.17 & 1.94 & - & 124.5 & 1.29 & 1.55 & 2.05 & - & 115.0 \\
\hline $\begin{array}{c}\text { GTP-C3'॰/R266/R268 } \\
\text { (PPP + guanine restraints) }\end{array}$ & $3^{-}$ & 0.00 & 3.15 & 1.93 & - & 158.8 & 17.72 & 2.17 & 1.80 & - & 125.8 & 1.55 & 1.56 & 1.88 & - & 118.8 \\
\hline $\begin{array}{c}\text { GTP-C3'•/R17(+)/R266/R268 } \\
\text { (PPP + guanine restraints) }\end{array}$ & 3 & 0.00 & 3.13 & 1.95 & 3.62 & 152.7 & 14.21 & 2.16 & 1.80 & 2.32 & 127.4 & -0.36 & 1.57 & 1.96 & 2.00 & 120.8 \\
\hline $\begin{array}{c}\text { GTP-C3'•/R17(0)/R266/R268 } \\
\text { (PPP + guanine restraints) }\end{array}$ & $3^{\circ}$ & 0.00 & 3.17 & 1.89 & 3.70 & 155.3 & 18.21 & 2.14 & 2.05 & 2.61 & 127.1 & 1.14 & 1.55 & - & $-{ }^{f}$ & 121.3 \\
\hline $\begin{array}{c}\text { GTP-C3'•/K17(+)/R266/R268 } \\
\text { (PPP + guanine restraints) }\end{array}$ & 4 & 0.00 & 2.86 & 1.65 & 1.93 & 123.3 & 4.86 & 2.22 & 1.64 & 1.88 & 120.1 & -18.78 & 1.55 & 1.74 & 1.83 & 118.2 \\
\hline $\begin{array}{c}\text { GTP-C3'•/K17(0)/R266/R268 } \\
\text { (PPP + guanine restraints) }\end{array}$ & $4^{\circ}$ & 0.00 & 3.21 & 1.90 & 4.74 & 156.3 & 18.04 & 2.18 & 1.77 & 2.69 & 124.5 & 0.34 & 1.56 & 1.86 & 2.36 & 118.6 \\
\hline
\end{tabular}

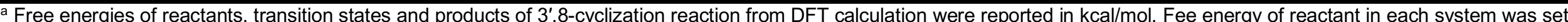

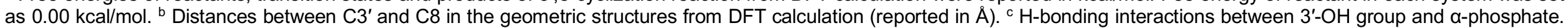

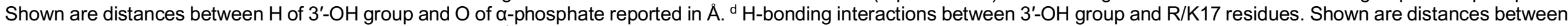

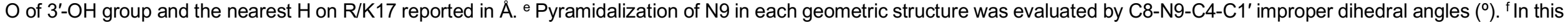
structure, $3^{\prime}-\mathrm{OH}$ is $\mathrm{H}$-bonded with deprotonated $\mathrm{R} 17$ but with $3^{\prime}-\mathrm{OH}$ as an $\mathrm{H}$-bond donor as opposed to an $\mathrm{H}$-bond acceptor in the other cases. 
Table S5. Geometric structures from 4 systems not shown in main contents

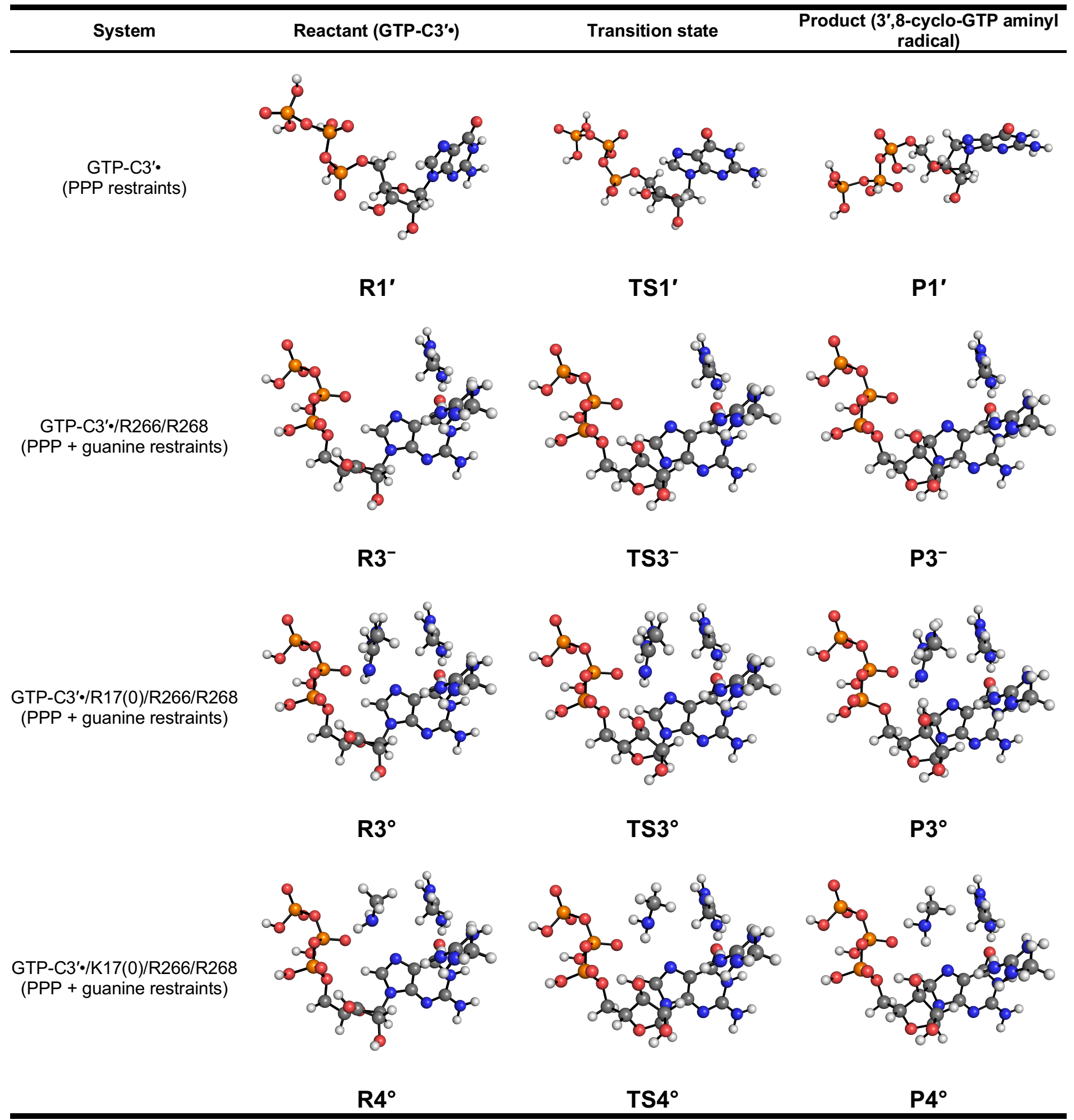



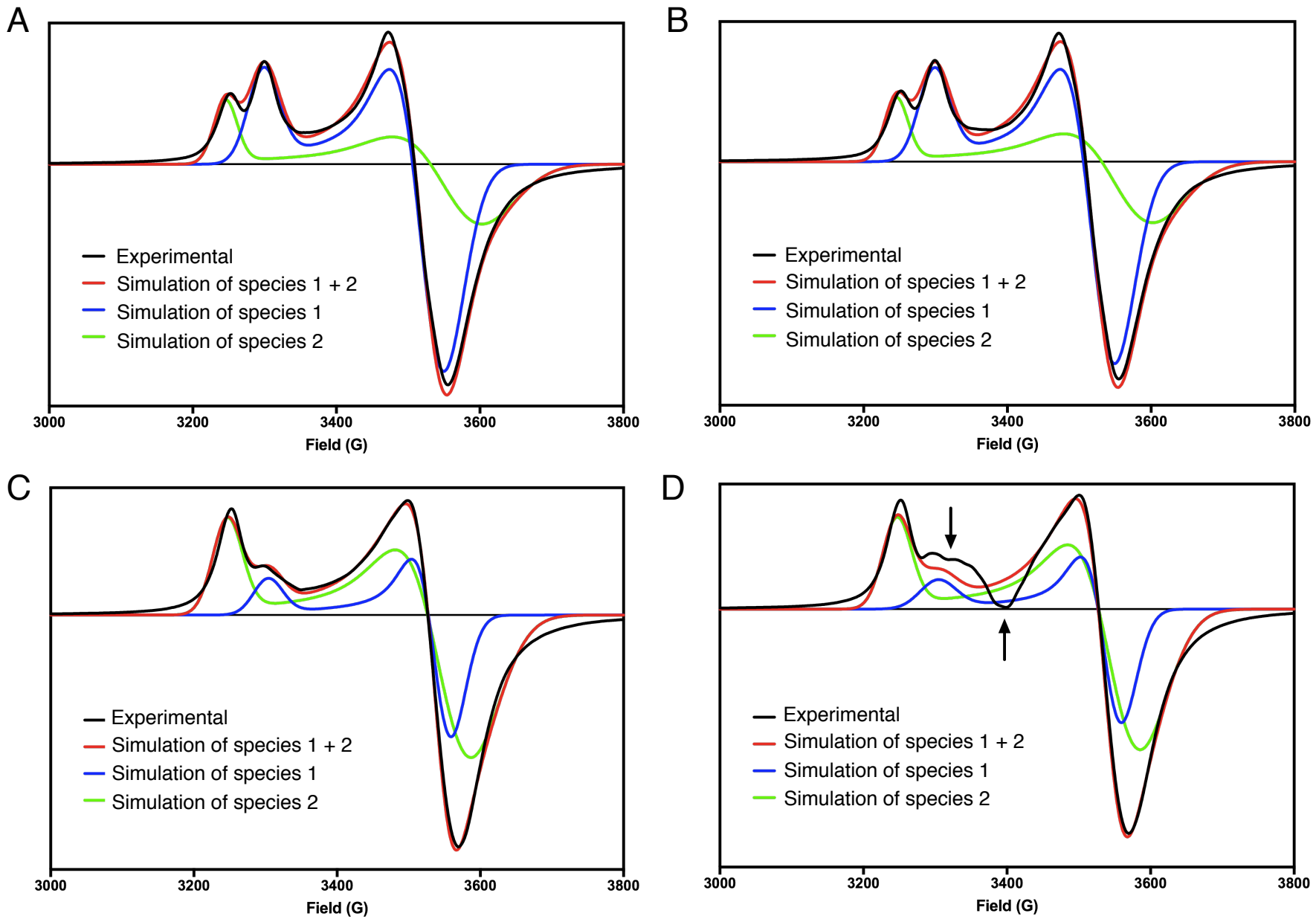

Figure S1. EPR spectra of MoaA at $15 \mathrm{~K}$.

Pre-reduced MoaA was incubated with (A) buffer only, (B) SAM, (C) GTP, (D) both SAM and GTP for 2 min and manually frozen in an isopentane slush bath. The narrower signal was designated as species 1 , and the wider signal as species 2 . The $g$ values and the ratio of the two signals are listed in Table S1. 


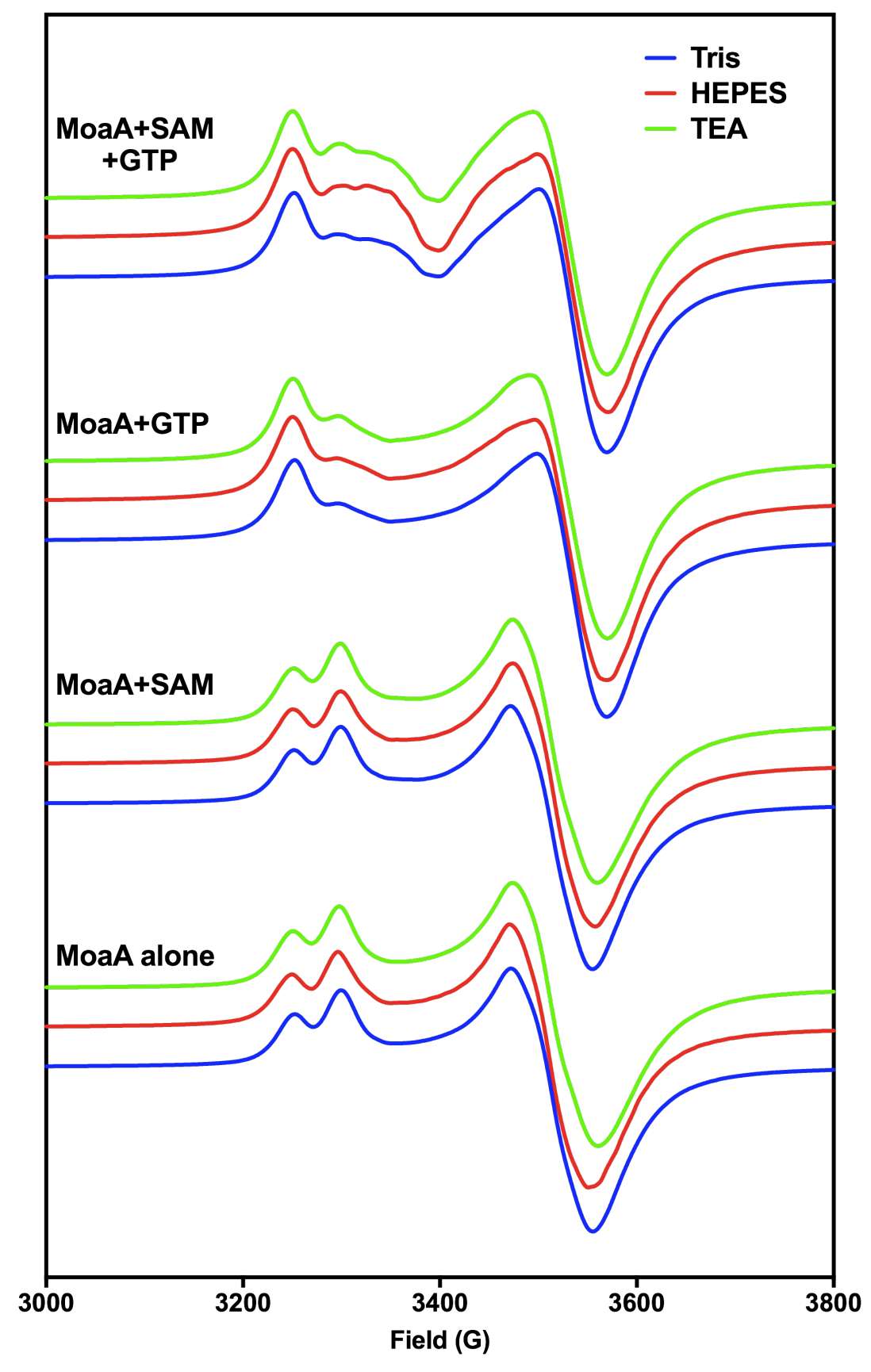

Figure S2. EPR characterization of MoaA [4Fe-4S] clusters in three different buffers at $15 \mathrm{~K}$.

Tris (blue traces): $100 \mathrm{mM}$ Tris (pH 7.6), $300 \mathrm{mM} \mathrm{NaCl}, 10 \%$ glycerol, $5 \mathrm{mM}$ DTT; HEPES (red traces): $50 \mathrm{mM}$ HEPES (pH 7.6), $150 \mathrm{mM} \mathrm{NaCl}, 10$ \% glycerol, 5 mM DTT; TEA (green traces): $100 \mathrm{mM}$ triethanolamine (pH 7.6), $300 \mathrm{mM} \mathrm{NaCl}, 10$ \% glycerol, 5 mM DTT. 


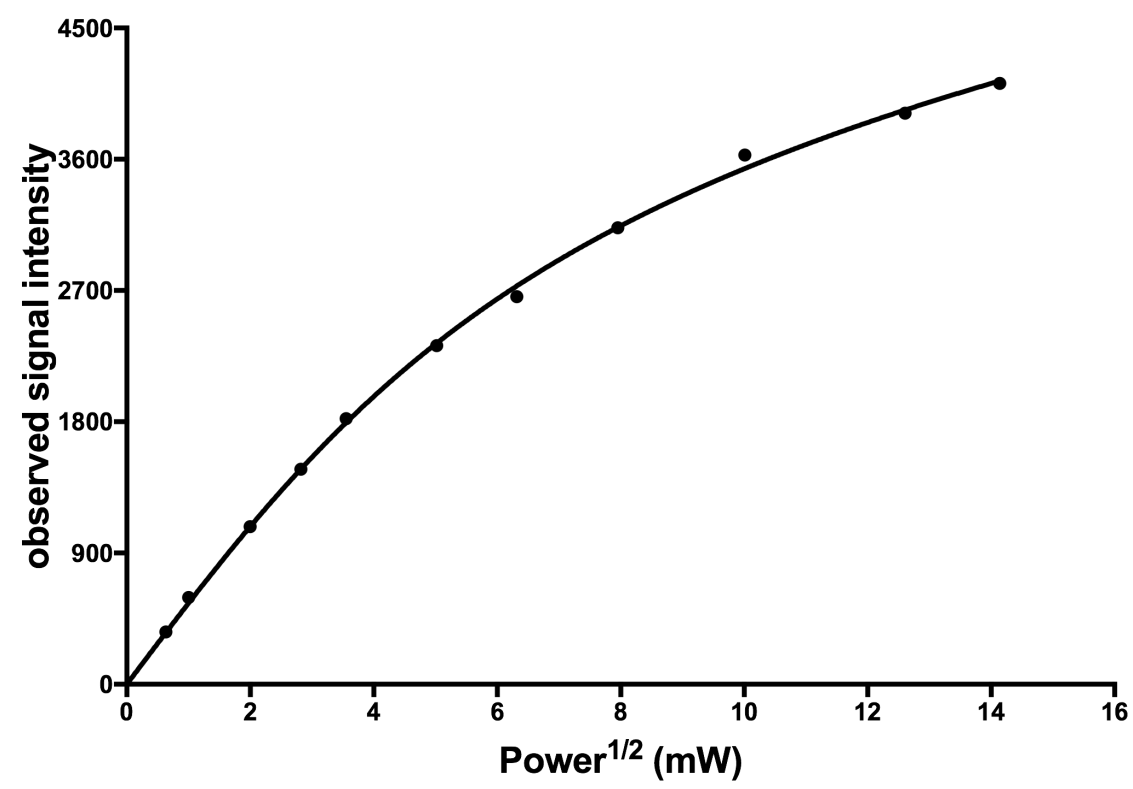

Figure S3. Microwave power saturation of radical $X$ signal at $45 \mathrm{~K}$.

The solid line represents a non-linear curve fit to eq. 1 with $K=561.5 \pm 15.4, P_{1 / 2}=34.5 \pm 10.8 \mathrm{~mW}$, and $b=$ $0.68 \pm 0.08$. 


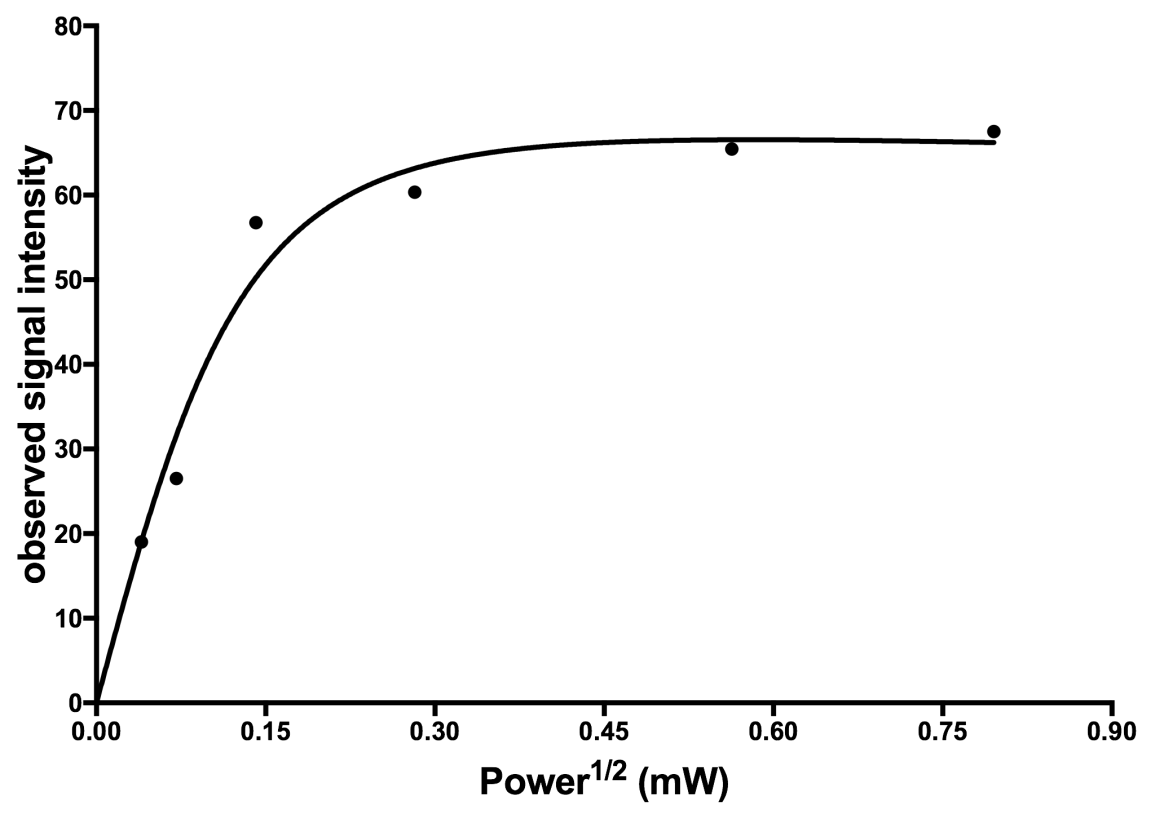

Figure S4. Microwave power saturation of the C-7' radical observed in C209A-PolH measured at $77 \mathrm{~K}$.

The solid line represents a non-linear curve fit to eq. 1 with $K=494.9 \pm 79.57, P_{1 / 2}=23.3 \pm 17.7 \mu \mathrm{W}$, and $b=$ $1.07 \pm 0.18$. C209A-PolH was prepared as previously reported ${ }^{11}$. 


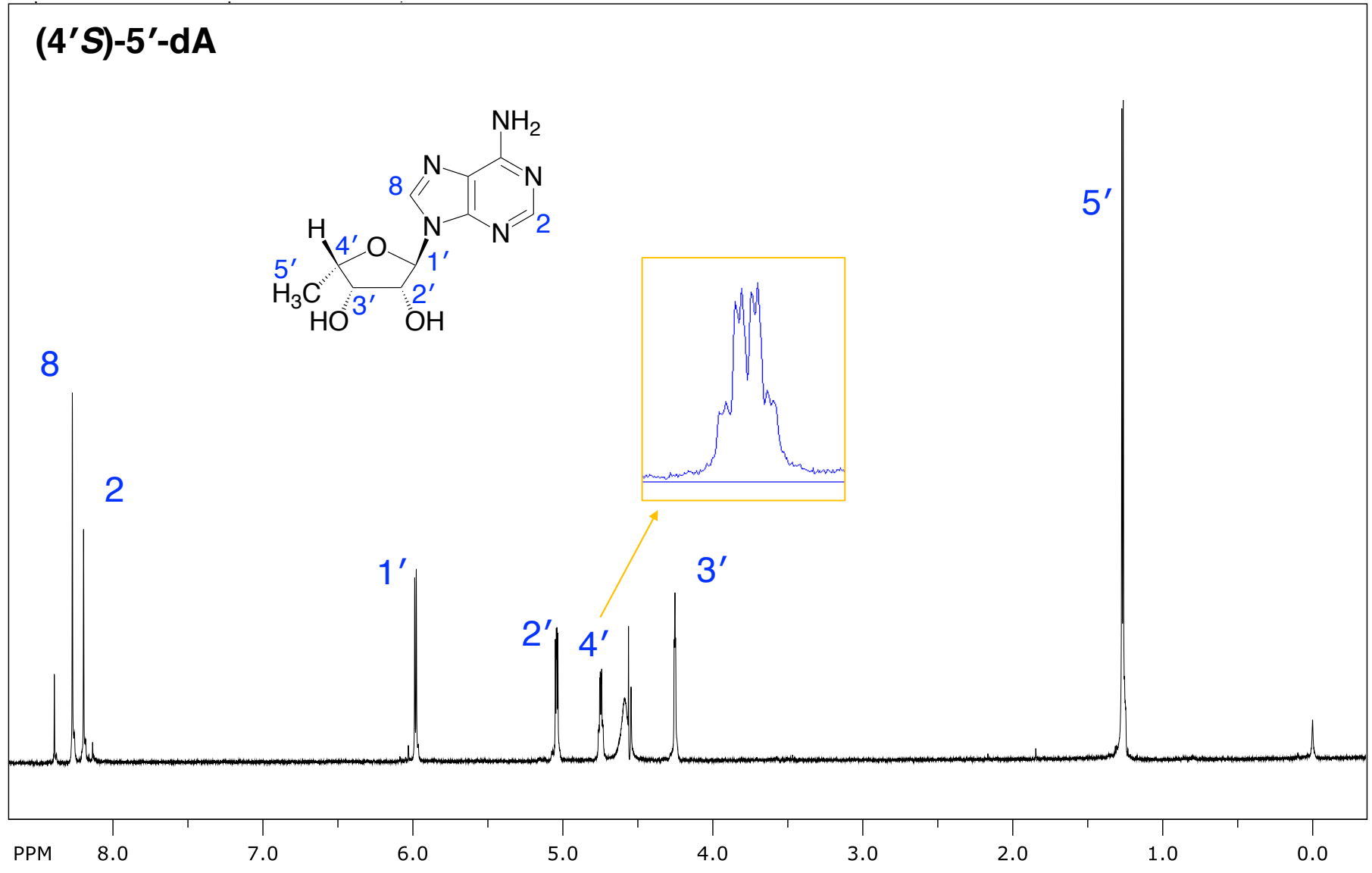

Figure S5. ${ }^{1} \mathrm{H}$ NMR (700 MHz) of (4'S)-5'-dA isolated from MoaA reaction.

${ }^{1} \mathrm{H}$ NMR $\left(\mathrm{D}_{2} \mathrm{O}, 313 \mathrm{~K}\right) \delta 1.27\left(\mathrm{~d}, 3 \mathrm{H}, \mathrm{H} 5^{\prime},{ }^{3} J_{4^{\prime}-5^{\prime}}=6.5 \mathrm{~Hz}\right) ; 4.25\left(\mathrm{t}, 1 \mathrm{H}, \mathrm{H} 3^{\prime}\right) ; 4.75\left(\mathrm{~m}, 1 \mathrm{H}, \mathrm{H} 4^{\prime},{ }^{3} J_{3^{\prime}-4^{\prime}}=2.6 \mathrm{~Hz},{ }^{3} J_{5^{\prime}-4^{\prime}}\right.$ $=6.5 \mathrm{~Hz}) ; 5.04\left(\mathrm{dd}, 1 \mathrm{H}, \mathrm{H} 2^{\prime},{ }^{3} J_{3^{\prime}-2^{\prime}}=4.3 \mathrm{~Hz},{ }^{3} J_{1^{\prime}-2^{\prime}}=7.3 \mathrm{~Hz}\right) ; 5.98\left(\mathrm{~d}, 1 \mathrm{H}, \mathrm{H} 1^{\prime},{ }^{3} J_{2^{\prime}-1^{\prime}}=7.3 \mathrm{~Hz}\right) ; 8.20(\mathrm{~s}, 1 \mathrm{H}, \mathrm{H} 2)$; $8.27(\mathrm{~s}, 1 \mathrm{H}, \mathrm{H} 8)$. 


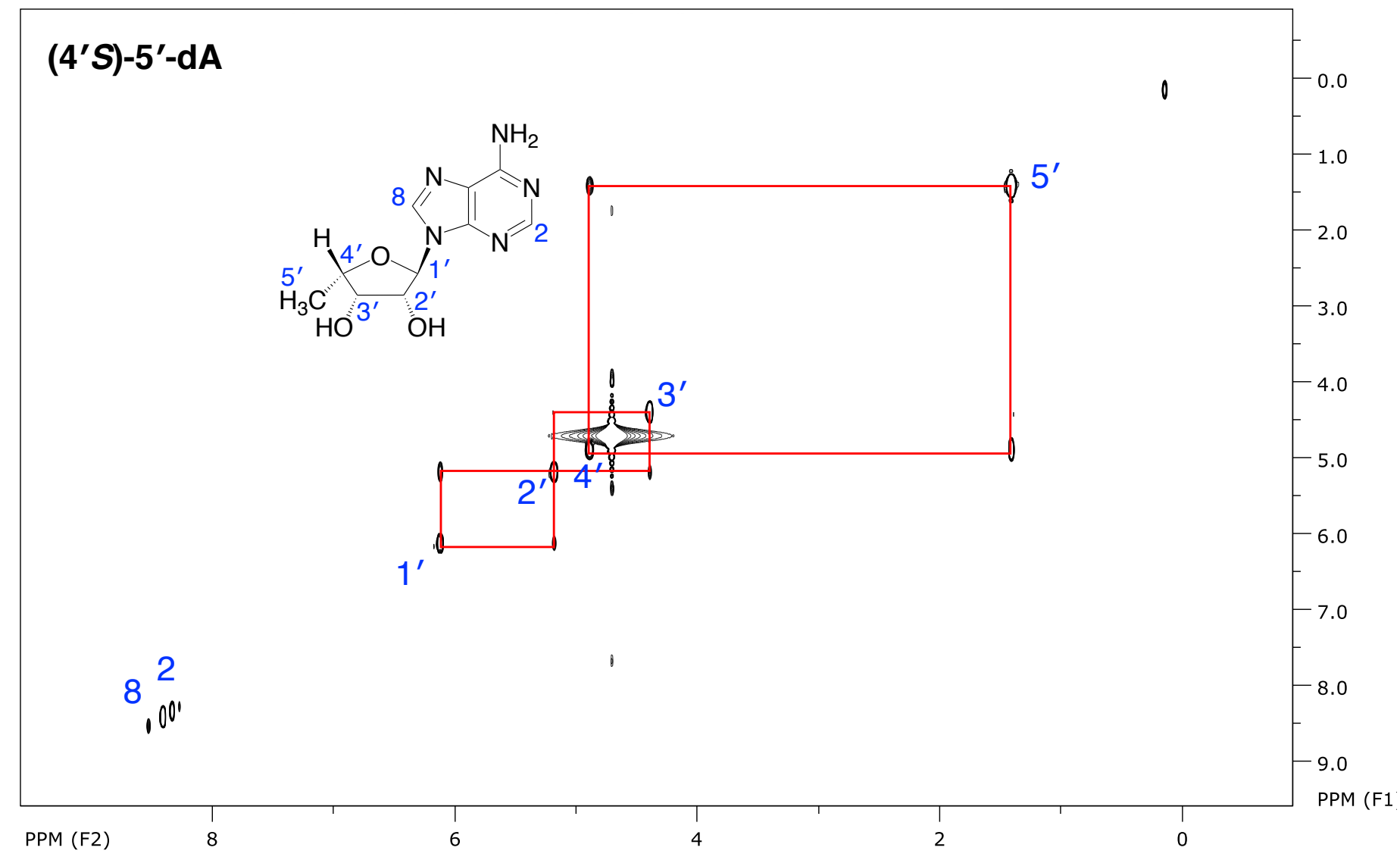

Figure S6. ${ }^{1} \mathrm{H}-{ }^{1} \mathrm{H}$ COSY $\left(700 \mathrm{MHz}, \mathrm{D}_{2} \mathrm{O}, 313 \mathrm{~K}\right)$ of $\left(4^{\prime} \mathrm{S}\right)-5^{\prime}-\mathrm{dA}$ isolated from MoaA reaction. 


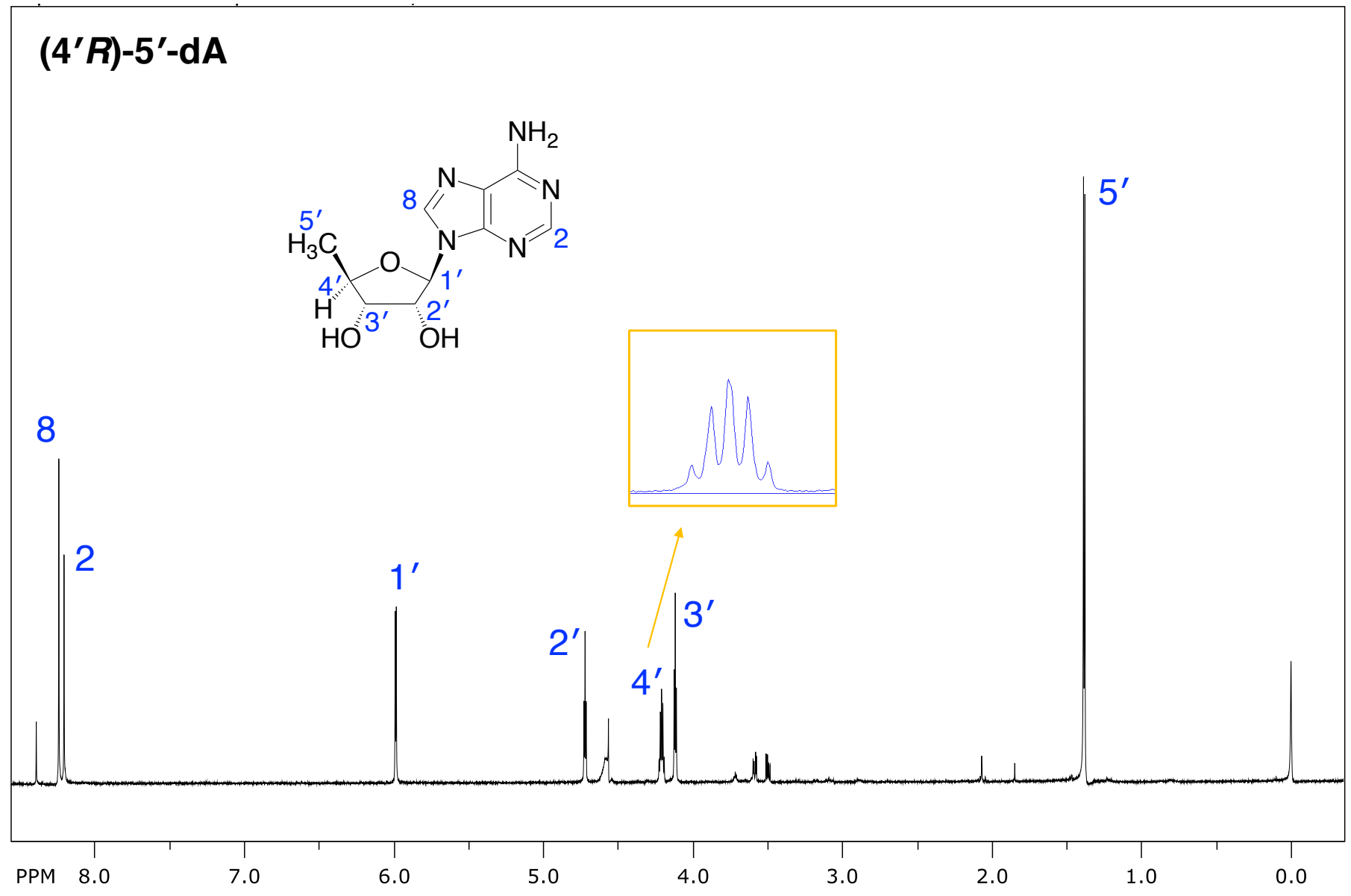

Figure S7. ${ }^{1} \mathrm{H}$ NMR (700 MHz) of (4'R)-5'-dA isolated from MoaA reaction.

${ }^{1} \mathrm{H}$ NMR $\left(\mathrm{D}_{2} \mathrm{O}, 313 \mathrm{~K}\right) \delta 1.38\left(\mathrm{~d}, 3 \mathrm{H}, \mathrm{H} 5^{\prime},{ }^{3} \mathrm{~J}_{4^{\prime}-5^{\prime}}=6.5 \mathrm{~Hz}\right) ; 4.12\left(\mathrm{t}, 1 \mathrm{H}, \mathrm{H} 3^{\prime},{ }^{3} J_{2^{\prime}-3^{\prime}}=5.2 \mathrm{~Hz},{ }^{3} J_{4^{\prime}-3^{\prime}}=5.2 \mathrm{~Hz}\right) ; 4.21(\mathrm{~m}$, $\left.1 \mathrm{H}, \mathrm{H} 4^{\prime},{ }^{3} J_{3^{\prime}-4^{\prime}}=5.2 \mathrm{~Hz},{ }^{3} J_{5^{\prime}-4^{\prime}}=6.5 \mathrm{~Hz}\right) ; 4.72\left(\mathrm{t}, 1 \mathrm{H}, \mathrm{H} 2^{\prime},{ }^{3} J_{3^{\prime}-2^{\prime}}=5.2 \mathrm{~Hz},{ }^{3} J_{1^{\prime}-2^{\prime}}=5.2 \mathrm{~Hz}\right) ; 5.99\left(\mathrm{~d}, 1 \mathrm{H}, \mathrm{H} 1^{\prime},{ }^{3} J_{2^{\prime}-1^{\prime}}=\right.$ $5.2 \mathrm{~Hz}) ; 8.21(\mathrm{~s}, 1 \mathrm{H}, \mathrm{H} 2) ; 8.24(\mathrm{~s}, 1 \mathrm{H}, \mathrm{H} 8)$. 


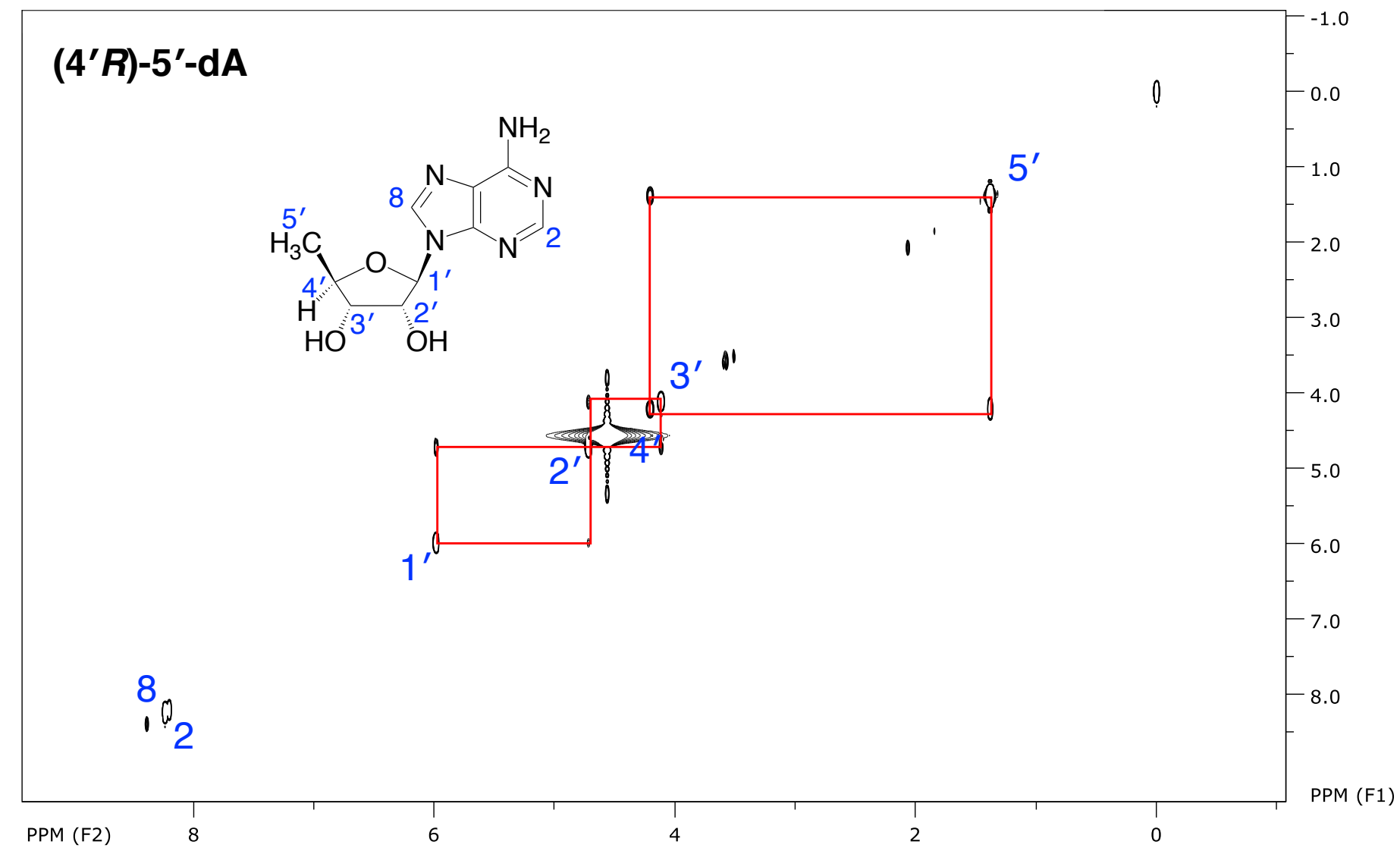

Figure S8. ${ }^{1} \mathrm{H}-{ }^{1} \mathrm{H} \operatorname{COSY}\left(700 \mathrm{MHz}, \mathrm{D}_{2} \mathrm{O}, 313 \mathrm{~K}\right)$ of $\left(4^{\prime} R\right)-5^{\prime}-\mathrm{dA}$ isolated from MoaA reaction. 

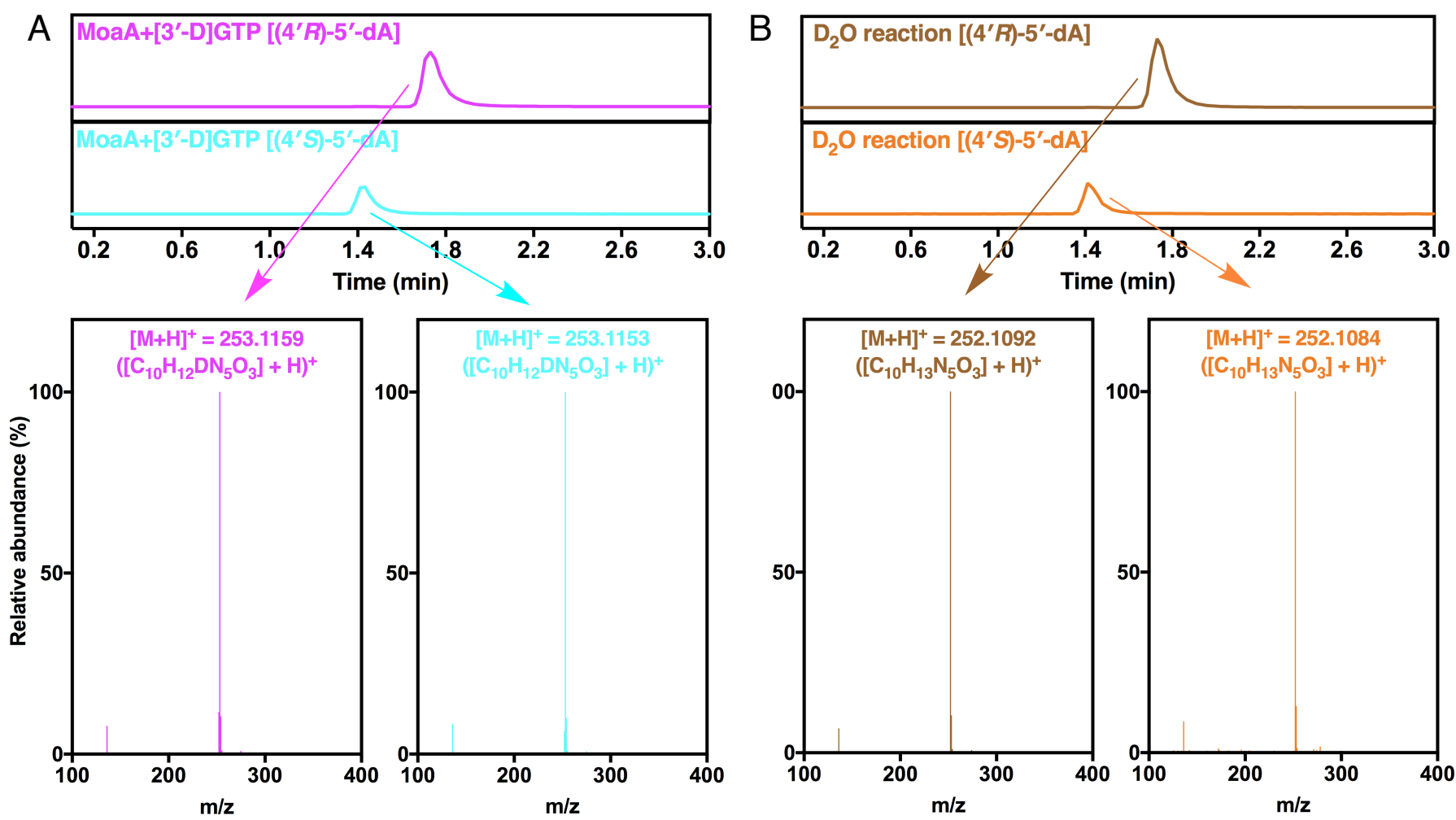

Figure S9. LCMS of (4'R)- and (4'S)-5'-dA formed in MoaA assay with [3'--2 H]GTP (A) or in ${ }^{2} \mathrm{H}_{2} \mathrm{O}(\mathrm{B})$.

Shown are extracted ion chromatograms monitored at $\mathrm{m} / \mathrm{z}=253.1154 \pm 0.0025(\mathrm{~A})$ and $\mathrm{m} / \mathrm{z}=252.1091 \pm 0.0024$

(B) and extracted mass spectra at the following retention time: $(A)\left(4^{\prime} R\right)-5^{\prime}-d A: 1.693 \sim 1.875$ min, (4'S)-5'-dA: 1.400 $1.558 \mathrm{~min}) ;(B)\left(4^{\prime} R\right)-5^{\prime}-\mathrm{dA}: 1.717 \sim 1.853 \mathrm{~min},\left(4^{\prime} \mathrm{S}\right)-5^{\prime}-\mathrm{dA}: 1.384 \sim 1.543 \mathrm{~min}$. 


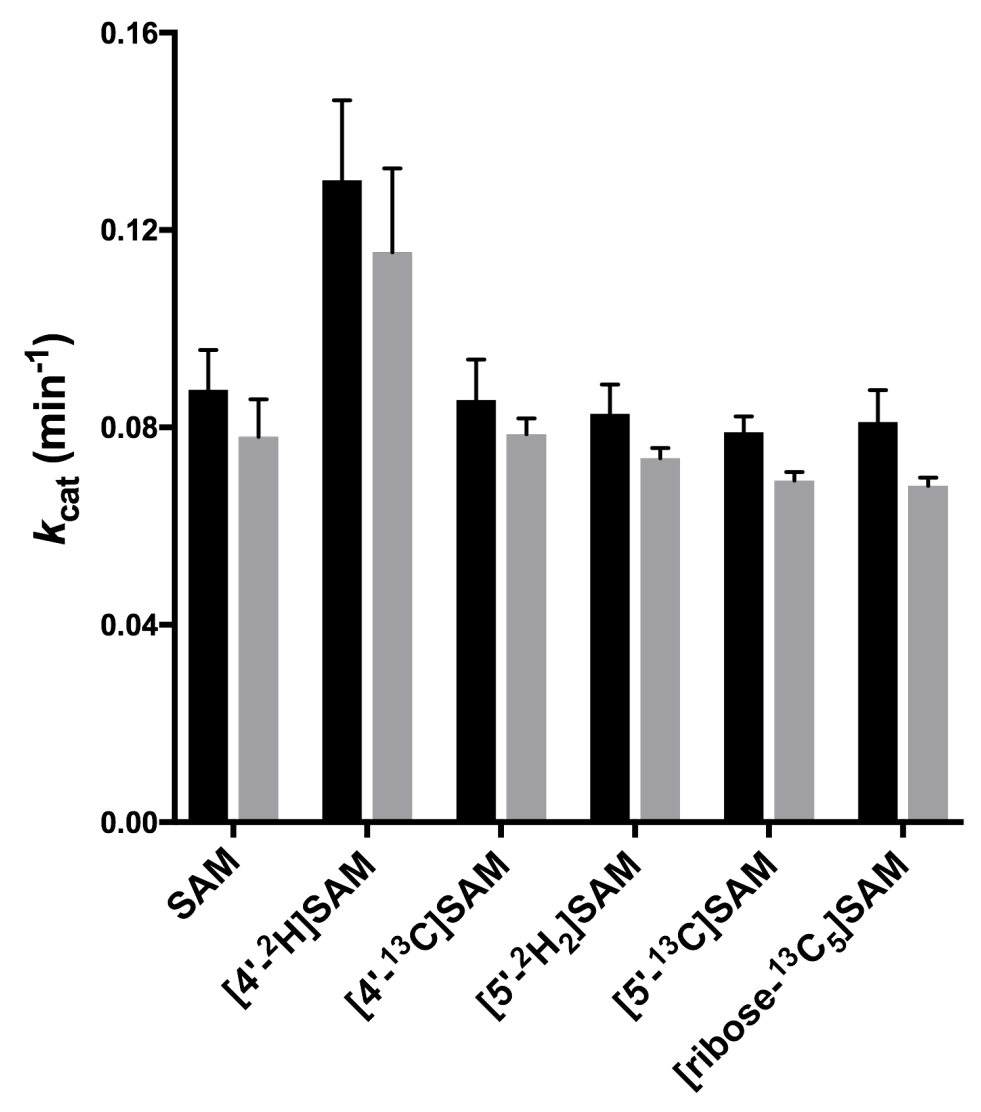

Figure S10. MoaA activity with non-labeled or isotopically labeled SAM.

MoaA $(30 \mu \mathrm{M})$ / MoaC $(60 \mu \mathrm{M})$ coupled assays with SDT (1 mM), GTP (1 mM), and SAM or isotopically-labeled SAM ( $1 \mathrm{mM}$ ) were carried out. Kinetics of formations of Compound $Z$ and $\left(4^{\prime} R\right)-5^{\prime}-\mathrm{dA}$ were quantified. Error bars represent standard deviations from three independent reactions. 


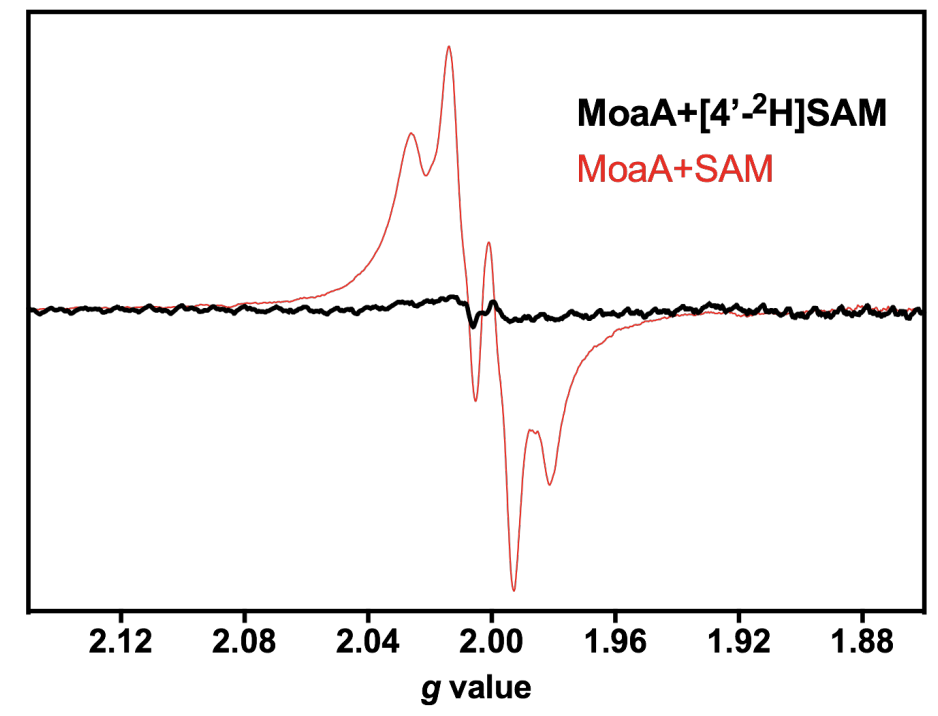

Figure S11. Overlay of EPR spectra of MoaA reaction with GTP and SAM or [4'-2H]SAM.

MoaA $(300 \mu \mathrm{M})$ was incubated with GTP $(1 \mathrm{mM})$ and SAM or [4'-2 $\mathrm{H}$ ]SAM $(1 \mathrm{mM})$ in the presence of sodium dithionite $(1 \mathrm{mM})$ at $25^{\circ} \mathrm{C}$ for $2 \mathrm{~min}$. The reactions were quenched by manually submerging them in isopentane slush bath, and EPR spectra were determined at $45 \mathrm{~K}$. Residual [4Fe-4S] ${ }^{1+}$ signals were subtracted out using a control reaction of MoaA with GTP in the absence of SAM. Shown are EPR spectra of the MoaA reaction with SAM (red trace), and that with $\left[4^{\prime}-{ }^{2} \mathrm{H}\right] \mathrm{SAM}$ (black trace). 


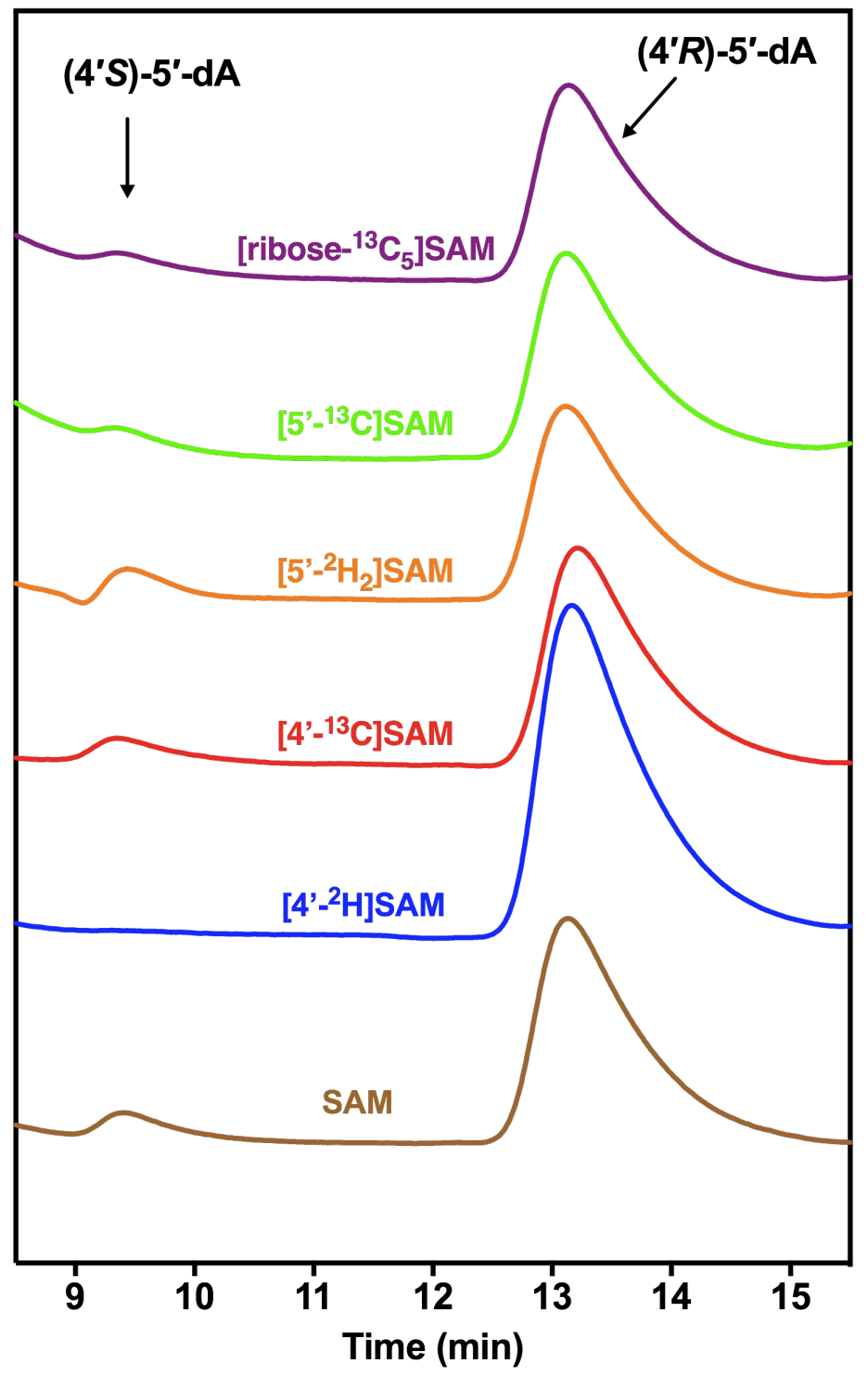

Figure S12. Formations of (4'S)-5'-dA in MoaA assays with non-labeled or isotopically labeled SAM.

Shown are HPLC traces monitored at $260 \mathrm{~nm}$ for MoaA $(30 \mu \mathrm{M}) / \mathrm{MoaC}(60 \mu \mathrm{M})$ coupled assays with (from the bottom to the top) SAM, [4'-2 H]SAM, $\left[4^{\prime}-{ }^{13} \mathrm{C}\right] \mathrm{SAM},\left[5^{\prime}-{ }^{2} \mathrm{H}_{2}\right] \mathrm{SAM},\left[5^{\prime}-{ }^{13} \mathrm{C}\right] \mathrm{SAM}$, [ribose- $\left.{ }^{13} \mathrm{C}_{5}\right] \mathrm{SAM}$ quenched at 600 s. HPLC was performed with $7.5 \%$ methanol in ammonium formate $(\mathrm{pH} \mathrm{4.5)}$ at a flow rate of $1 \mathrm{~mL} / \mathrm{min}$. Under this condition, (4'S)-5'-dA was eluted at $9.1 \mathrm{~min}$ and $\left(4^{\prime} R\right)-5^{\prime}-\mathrm{dA}$ was at $12.6 \mathrm{~min}$. 


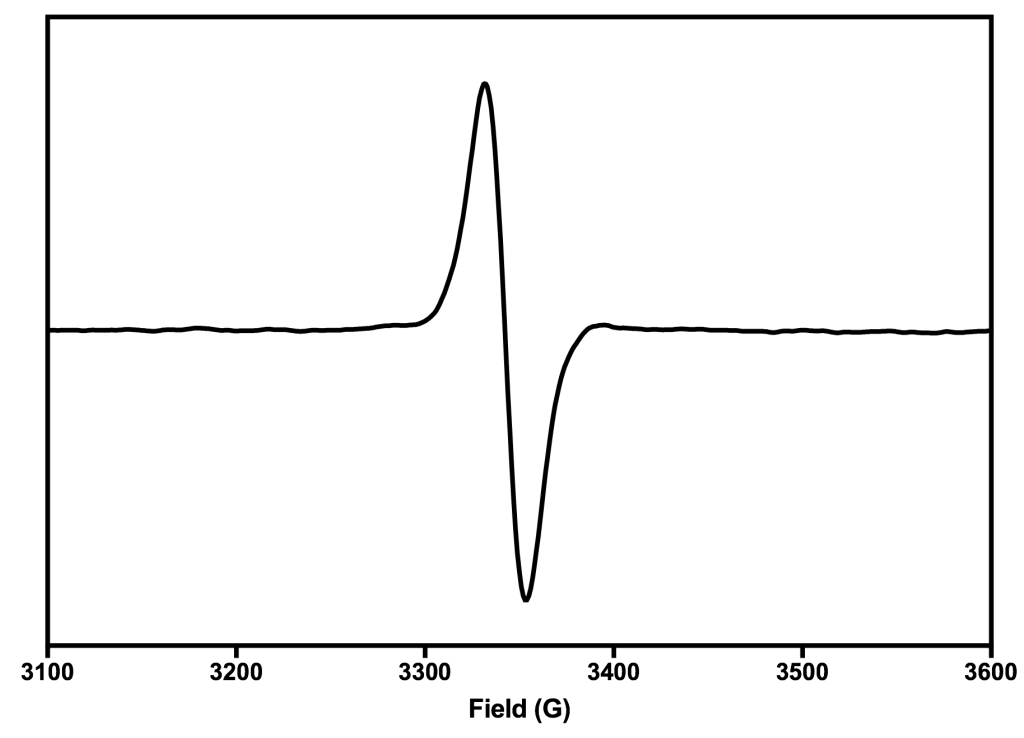

Figure S13. EPR spectrum of $18.0 \mu \mathrm{M}$ flavosemiquinone radical at $45 \mathrm{~K}$. 


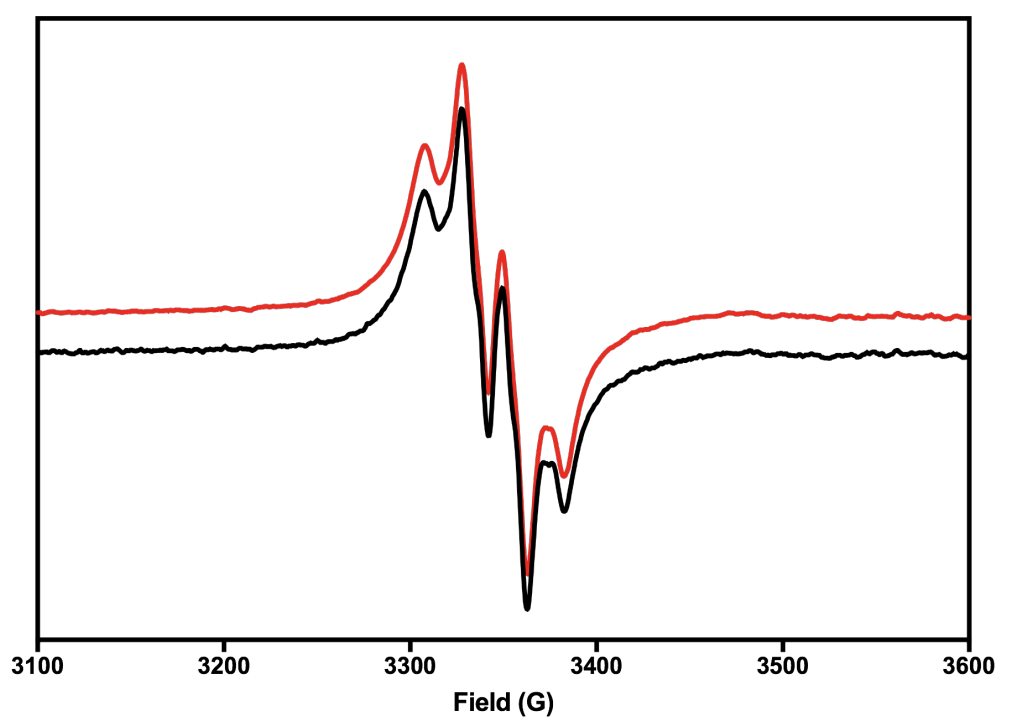

Figure S14. Comparison of the radical signals in MoaA assay (black) and MoaA/MoaC coupled assay (red).

Both samples were quenched at 2 min in an isopentane slush bath. 
A

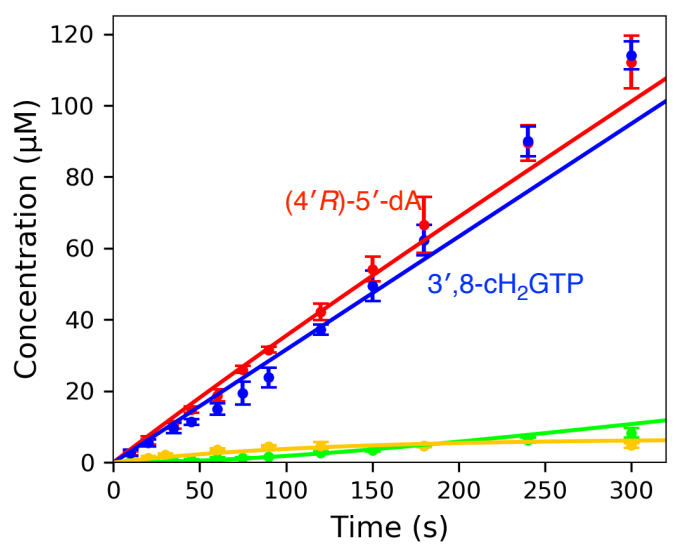

B

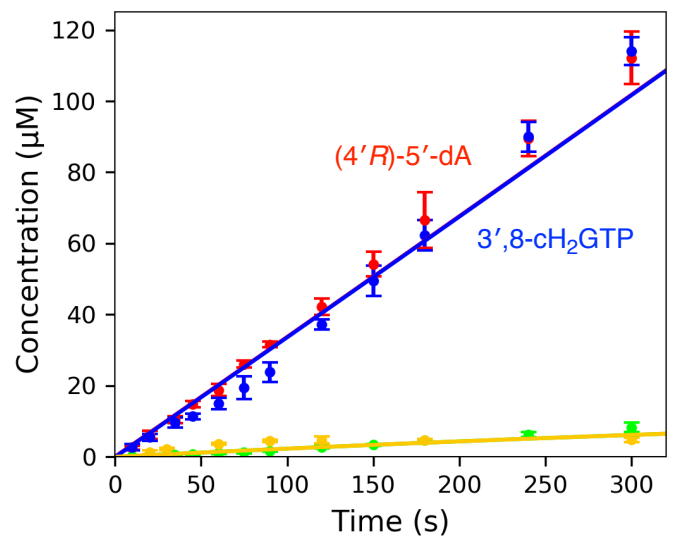

C

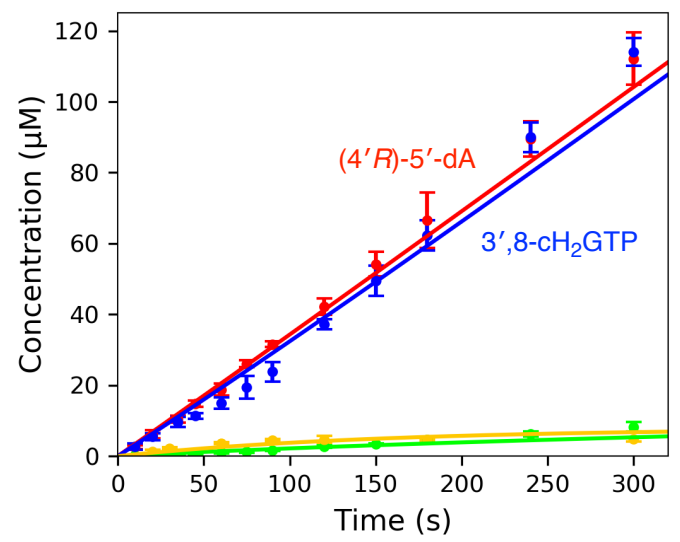

D

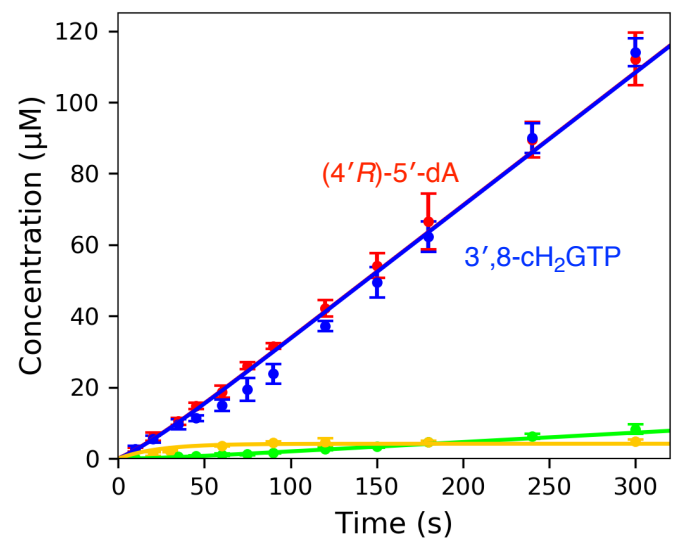

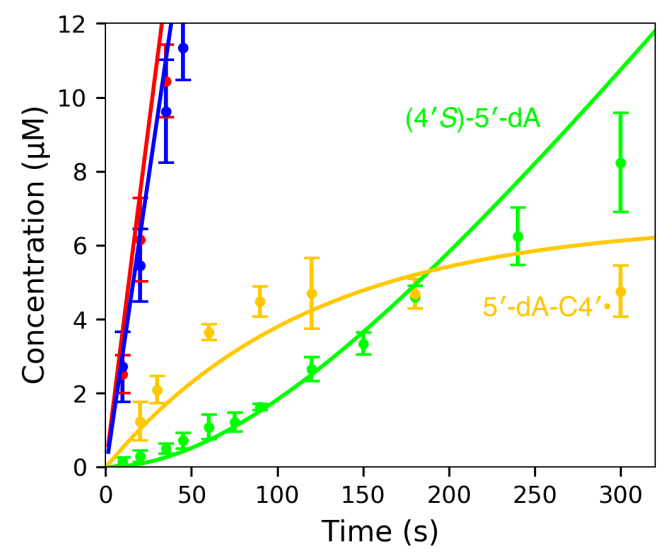
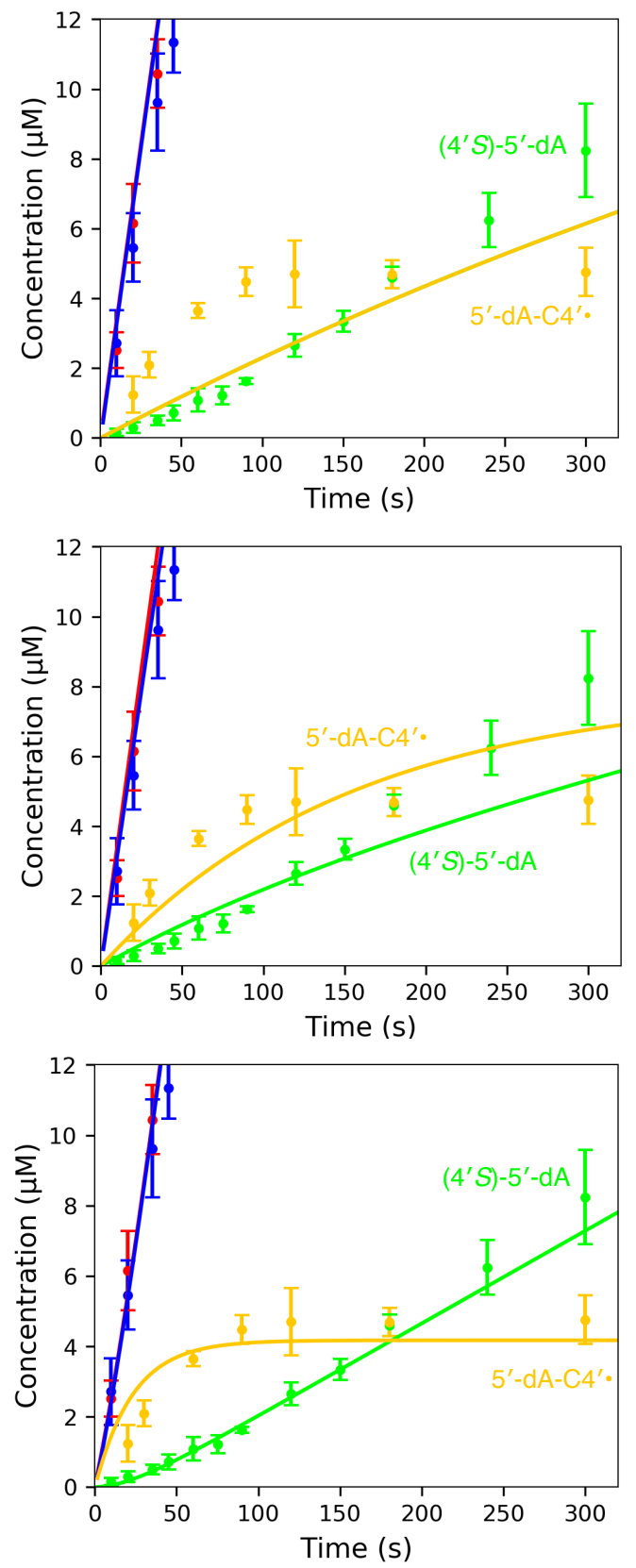

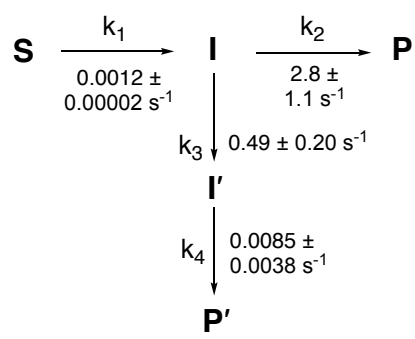

p-value: $1.19 \times 10^{-10}$ $X^{2} /$ DoF: 2.80

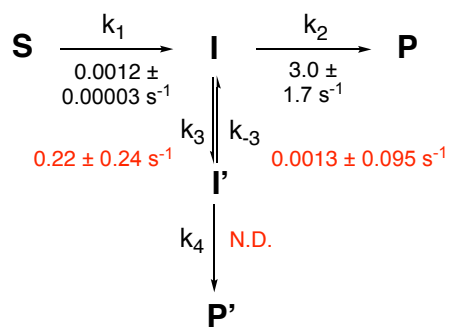

p-value: $3.12 \times 10^{-37}$ $\mathrm{X}^{2} / \mathrm{DoF}: 5.99$

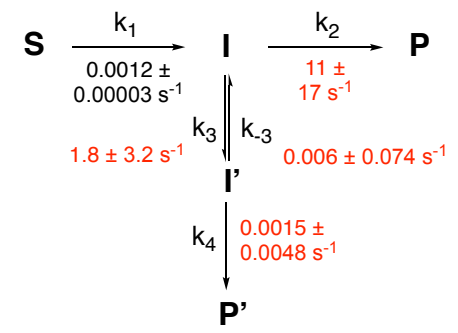

p-value: $1.34 \times 10^{-14}$ $X^{2} /$ DoF: 3.35

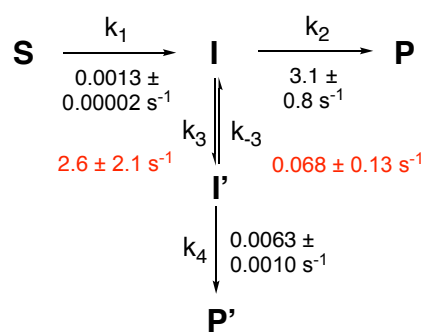

p-value: 0.071 $\mathrm{X}^{2} / \mathrm{DoF}: 1.31$ 

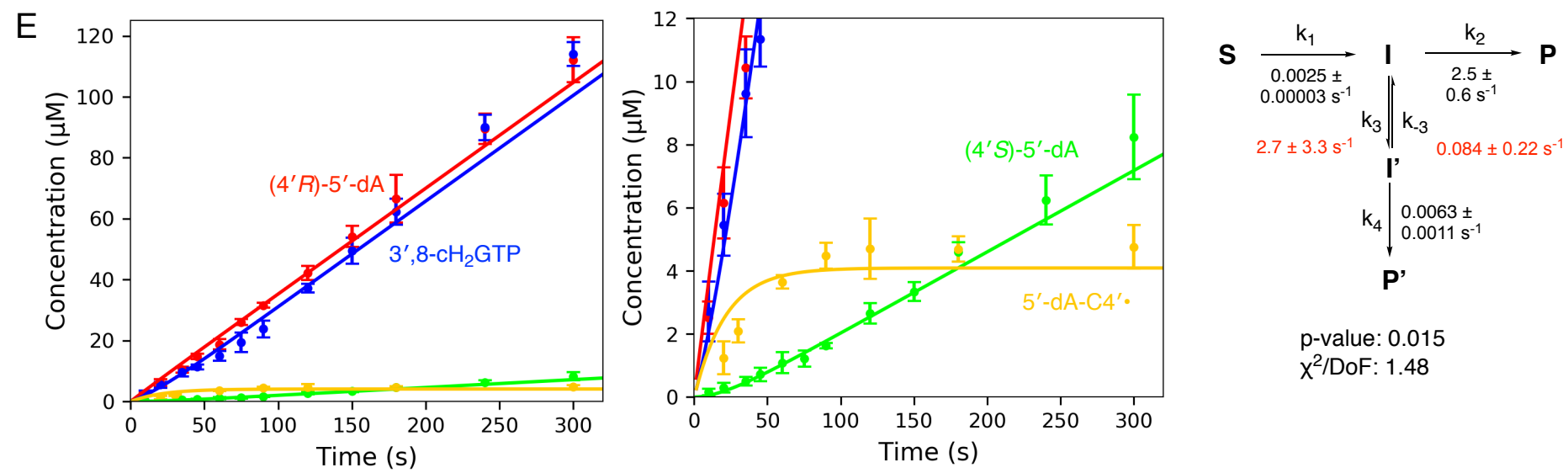

p-value: 0.015

$\mathrm{X}^{2} / \mathrm{DoF}: 1.48$
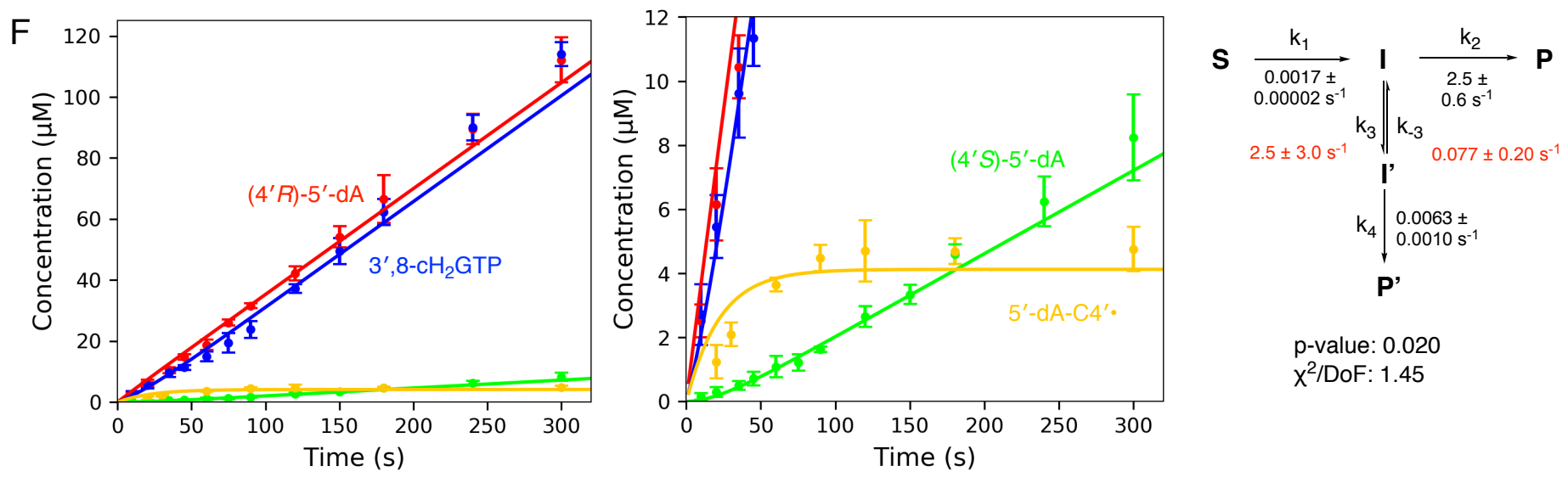

p-value: 0.020

$\mathrm{X}^{2} / \mathrm{DoF}: 1.45$
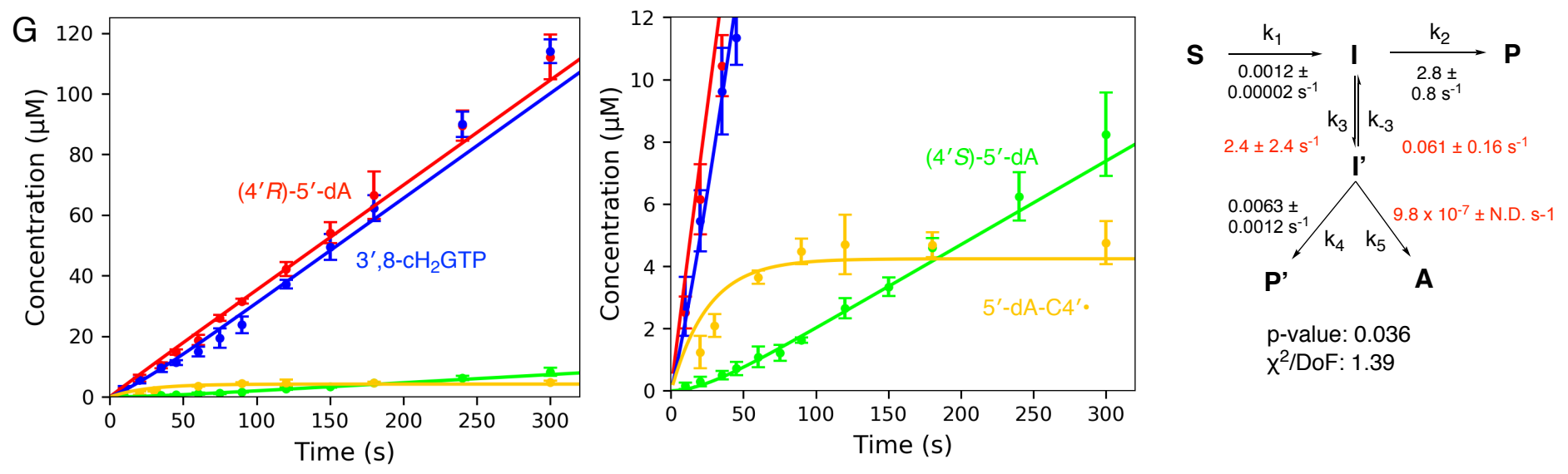

Figure S15. Kinetic fitting of MoaA catalysis with different models.

(A) The transformation of I to I' was set as irreversible. (B, C and D) In these analyses, it was assumed that upon acid quenching, 5'-dA-C4'• was converted to (B) (4'S)-5'-dA, (C) both (4'S)-5'-dA and (4'R)-5'-dA in a 1:1 ratio, or (D) other unidentified molecules. ( $E$ and $F$ ) The concentration of the Michaelis complex (S) were set as 150 $\mu \mathrm{M}(\mathrm{E})$ or $225 \mu \mathrm{M}(\mathrm{F})$. (G) In this model, 5'-dA-C4'• was converted to both (4'S)-5'-dA ( $\left.\mathbf{P}^{\prime}\right)$ and (4'R)-5'-dA (A).

Kinetic analysis

The concentration of the Michaelis complex (S) was set as an invariable at $300 \mu \mathrm{M}$ based on the low $K_{d}$ values $(3 \sim 5 \mu \mathrm{M})$ and excess amounts $(1 \mathrm{mM})$ of SAM and GTP used in all the assays relative to MoaA (300 
$\mu M)$. The amount of I was set below the EPR detection limit $(0.2 \mu \mathrm{M})$ because no detectable amount of GTPC3'• was observed in our EPR characterizations.

Reversibility of each step was determined by either the kinetic fitting or available biochemical evidences. The reversibility of SAM cleavage and subsequent $\mathrm{H}$-atom abstraction can be probed by the number of deuterium atoms incorporated into $5^{\prime}-\mathrm{d} A$ from the substrate. While multiple deuterium atoms were found in $5^{\prime}-\mathrm{d} A$ formed by radical SAM enzymes that catalyze reversible SAM cleavage and $\mathrm{H}$-atom abstraction ${ }^{12-14}$, MoaA produced only singly deuterated 5'-dA from [3'- $\left.{ }^{2} \mathrm{H}\right] \mathrm{GTP}{ }^{15}$. Therefore, $\mathbf{S} \rightarrow \mathbf{I}$ was set irreversible. The product formation steps (I $\rightarrow \mathbf{P}, \mathbf{I}^{\prime} \rightarrow \mathbf{P}^{\prime}$ ) were also set irreversible because it is unlikely that the radicals are reversibly generated from these products. The reversibility of $5^{\prime}-\mathrm{dA}-\mathrm{C} 4^{\prime} \cdot$ formation from GTP-C3'• is unknown and both possibilities were investigated (Figure 4 and S15A). Irreversible 5'-dA-C4'• formation model (Figure S15A) resulted in poorer fit compared to the reversible model (Figure S15A and 4; $p$ values $1.2 \times 10^{-10}$ vs 0.063 ), suggesting that the data is more consistent with the reversible mechanism. However, the errors for $k_{3}$ and $k_{-3}$ were large, likely because GTP-C3'• was undetectable, leaving some ambiguity about the kinetic nature of the transformation between I and I'.

The acid quenching used for 5'-dA detection may have quenched the accumulated 5'-dA-C4'• to (4'R)-5'dA, (4'S)-5'-dA or other uncharacterized molecules. Therefore, we performed kinetic fitting for cases where the acid-quenching of 5'-dA-C4'• yielded only (4'R)-5'-dA (Figure 4), only (4'S)-5'-dA (Figure S15B), both (4'R)-5'-dA and (4'S)-5'-dA with a 1:1 ratio (Figure S15C) or other uncharacterized molecules (Figure S15D). Among these possibilities, the model in which the acid quenching converted $5^{\prime}-\mathrm{dA}-\mathrm{C} 4^{\prime} \cdot$ to $\left(4^{\prime} R\right)-5^{\prime}-\mathrm{dA}$ provided the best fit. The model where 5'-dA-C4'• is quenched as other uncharacterized molecules by acid also provided acceptable fitting parameters ( $p$-value of 0.071 and $x^{2} / D o F$ of 1.31 ), but it failed to reproduce the delay in the formation of $3^{\prime}, 8-$ $\mathrm{cH}_{2}$ GTP relative to that of $\left(4^{\prime} R\right)-5^{\prime}-\mathrm{dA}$ in the first $\sim 2 \mathrm{~min}$ (Figure S15D). Moreover, the $k_{2}$ from this model (3.1 \pm $\left.0.8 \mathrm{~s}^{-1}\right)$ is similar to that from the best fitted model $\left(2.7 \pm 0.7 \mathrm{~s}^{-1}\right)$.

The amount of Michaelis complex (S) may be lower than $300 \mu \mathrm{M}$ due to incomplete loading of [4Fe-4S] clusters. An estimation of $\sim 1.5$ eq. of [4Fe-4S] clusters per monomer were reconstituted successfully based on Ferrozine assay, and $\sim 1$ eq. of [4Fe-4S] clusters per monomer were reduced by SDT based on EPR characterization. Hence $150 \mu \mathrm{M}$ (Figure S15E) or $225 \mu \mathrm{M}$ (Figure S15F) of S were also tested for global fitting. Kinetic fitting with different amount of $\mathbf{S}$ only changed $k_{1}$ that represents rate determining step of the entire reaction. The $k_{2}$ and $k_{3}$ values were only minimally affected $\left(k_{2}=2.5 \sim 2.7 \mathrm{~s}^{-1}, k_{3}=1.9 \sim 2.7 \mathrm{~s}^{-1}\right.$, and $k_{-3}=0.050$ $\left.\sim 0.084 \mathrm{~s}^{-1}\right)$.

Another potential model is that reductive quenching of $5^{\prime}-\mathrm{dA}-\mathrm{C} 4$ '• in the shunt pathway yields not only (4'S)-5'-dA, but also (4'R)-5'-dA (Figure S15G). Kinetic fitting with inclusion of (4'R)-5'-dA (A) into the shunt pathway resulted in an extremely low rate constant for $\mathbf{I}^{\prime} \rightarrow \mathbf{A}$, indicating reductive quenching of 5'-dA-C4'• to $\left(4^{\prime} R\right)-5^{\prime}-\mathrm{dA}$ is unlikely. This is consistent with the absence of incorporation of a deuterium to (4'S)-5'-dA from solvent (Figure S9B), which suggested a specific mechanism of 5'-dA-C4'• quenching to form (4'S)-5'-dA. 


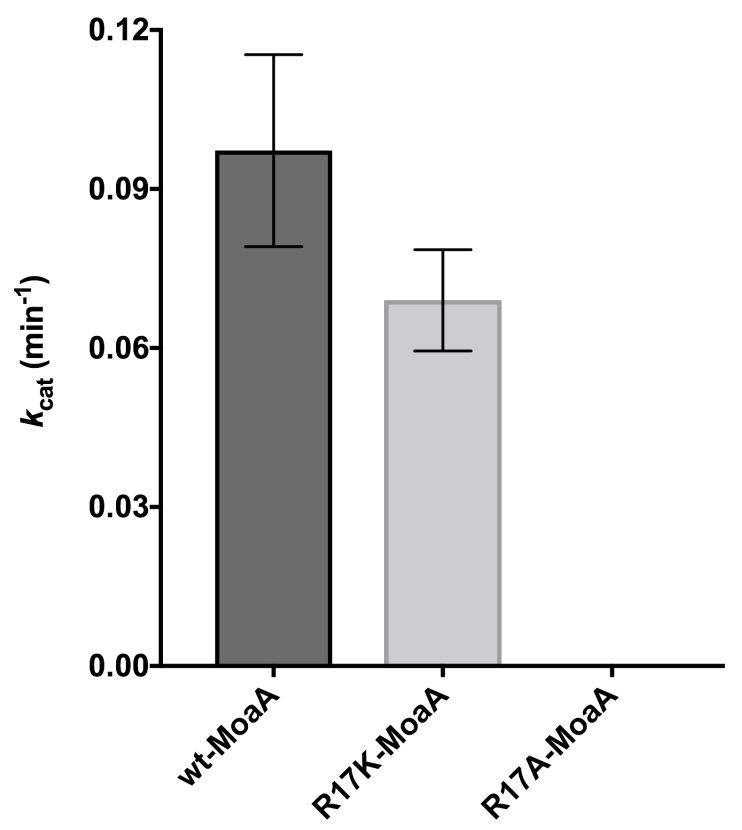

Figure S16. Activity of wt-, R17K- and R17A-MoaA.

Error bars represent standard deviations from four independent reactions. The activity of R17A-MoaA was below the detection limit. The $k_{\text {cat }}$ values for wt- and R17K-MoaA were $0.097 \pm 0.018$ and $0.069 \pm 0.010 \mathrm{~min}^{-1}$, respectively. 


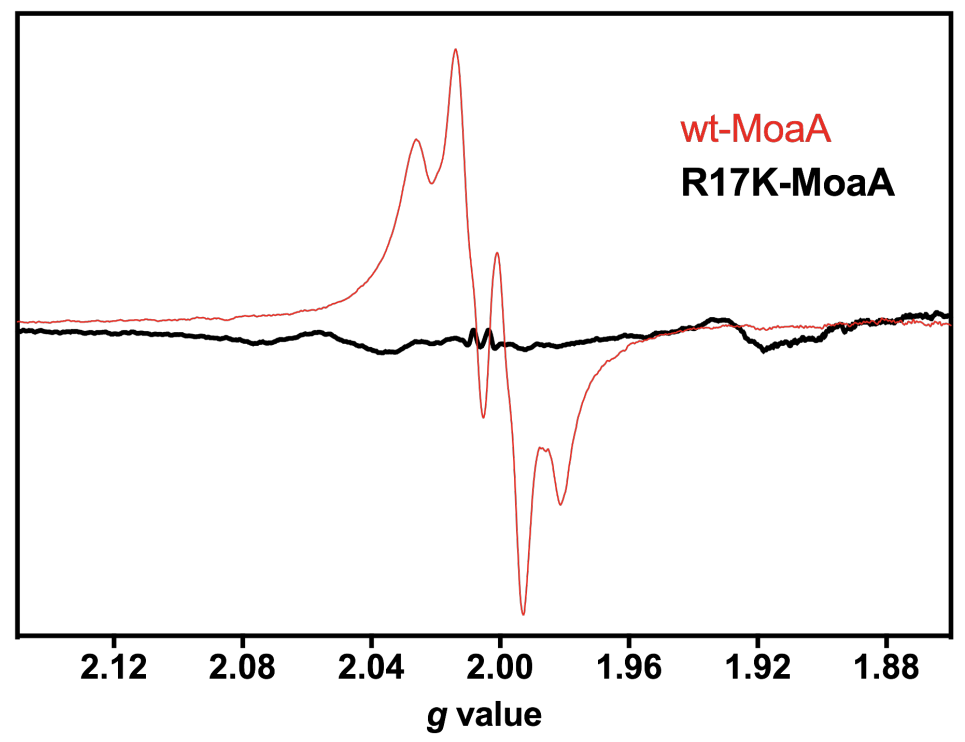

Figure S17. Overlay of EPR spectra of wt-MoaA and R17K-MoaA complete reactions.

Wt-MoaA or R17K-MoaA (300 $\mu \mathrm{M})$ was incubated with GTP $(1 \mathrm{mM})$, SAM (1 mM) and SDT (1 mM) for $2 \mathrm{~min}$ and the reactions were freeze quenched manually. Shown are EPR spectra at $45 \mathrm{~K}$ of a wt-MoaA reaction (red trace) and an R17K-MoaA reaction (black trace). Residual [4Fe-4S $]^{1+}$ cluster signals in the wt-MoaA spectrum were subtracted out using a control reaction without SAM, while $[4 \mathrm{Fe}-4 \mathrm{~S}]^{1+}$ cluster signals in the R17K-MoaA spectrum were subtracted out using a control reaction without GTP. 


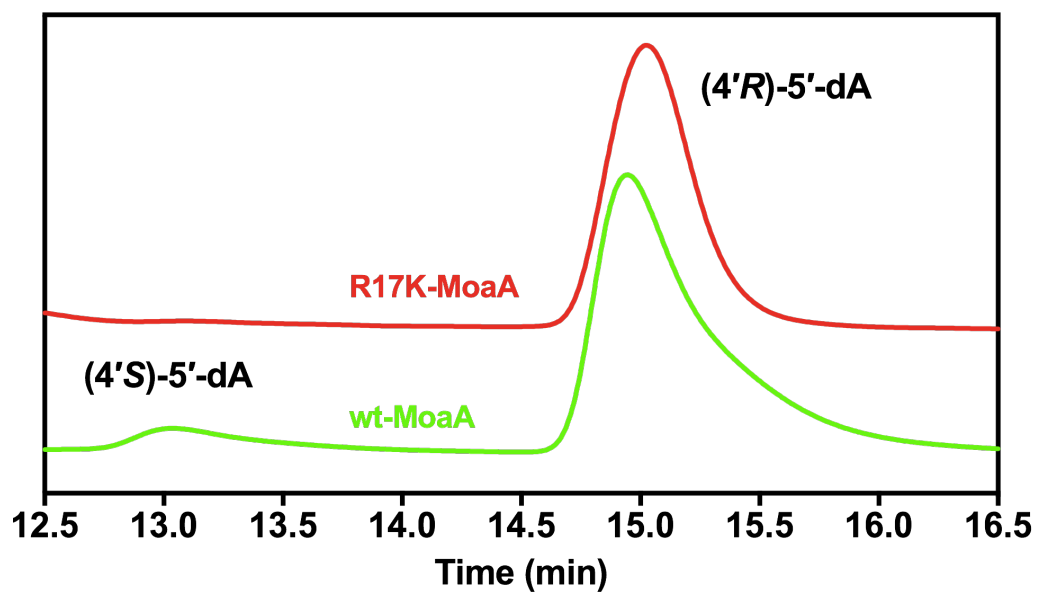

Figure S18. Formations of 5'-dA in wt- and R17K-MoaA assays.

Shown are HPLC traces monitored at $260 \mathrm{~nm}$ for wt-MoaA $(300 \mu \mathrm{M})$ / wt-MoaC $(300 \mu \mathrm{M})$ coupled assay (green trace) and R17K-MoaA (300 $\mu \mathrm{M}) /$ wt-MoaC (300 $\mu \mathrm{M})$ coupled assay (red trace). Both assays were quenched at $600 \mathrm{~s}$. 


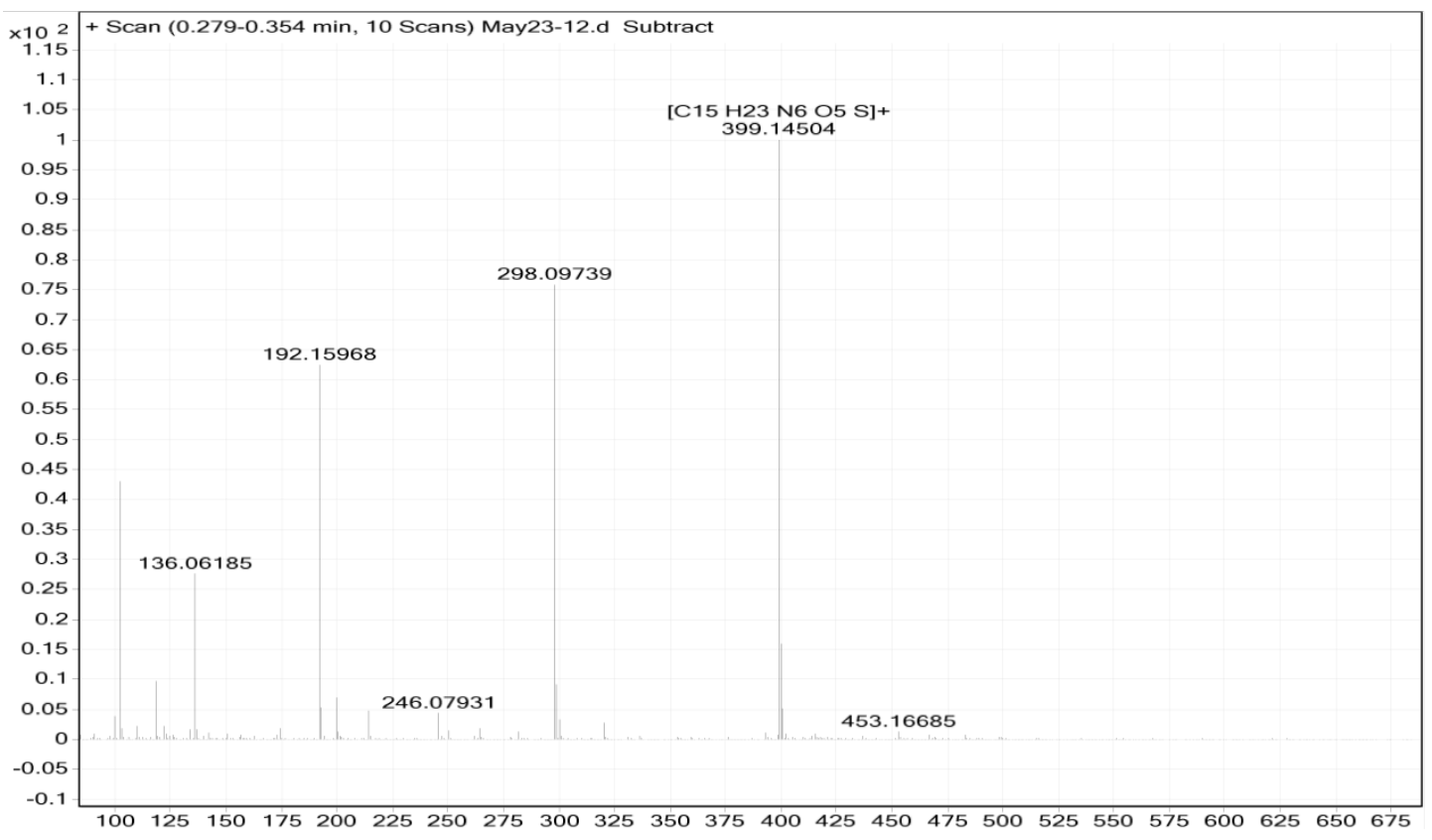

Figure S19. MS of enzymatically prepared non-labeled SAM.

$m / z \mathrm{M}^{+}$calculated for $\mathrm{C}_{15} \mathrm{H}_{23} \mathrm{~N}_{6} \mathrm{O}_{5} \mathrm{~S}^{+} 399.1451$; found 399.1450. 


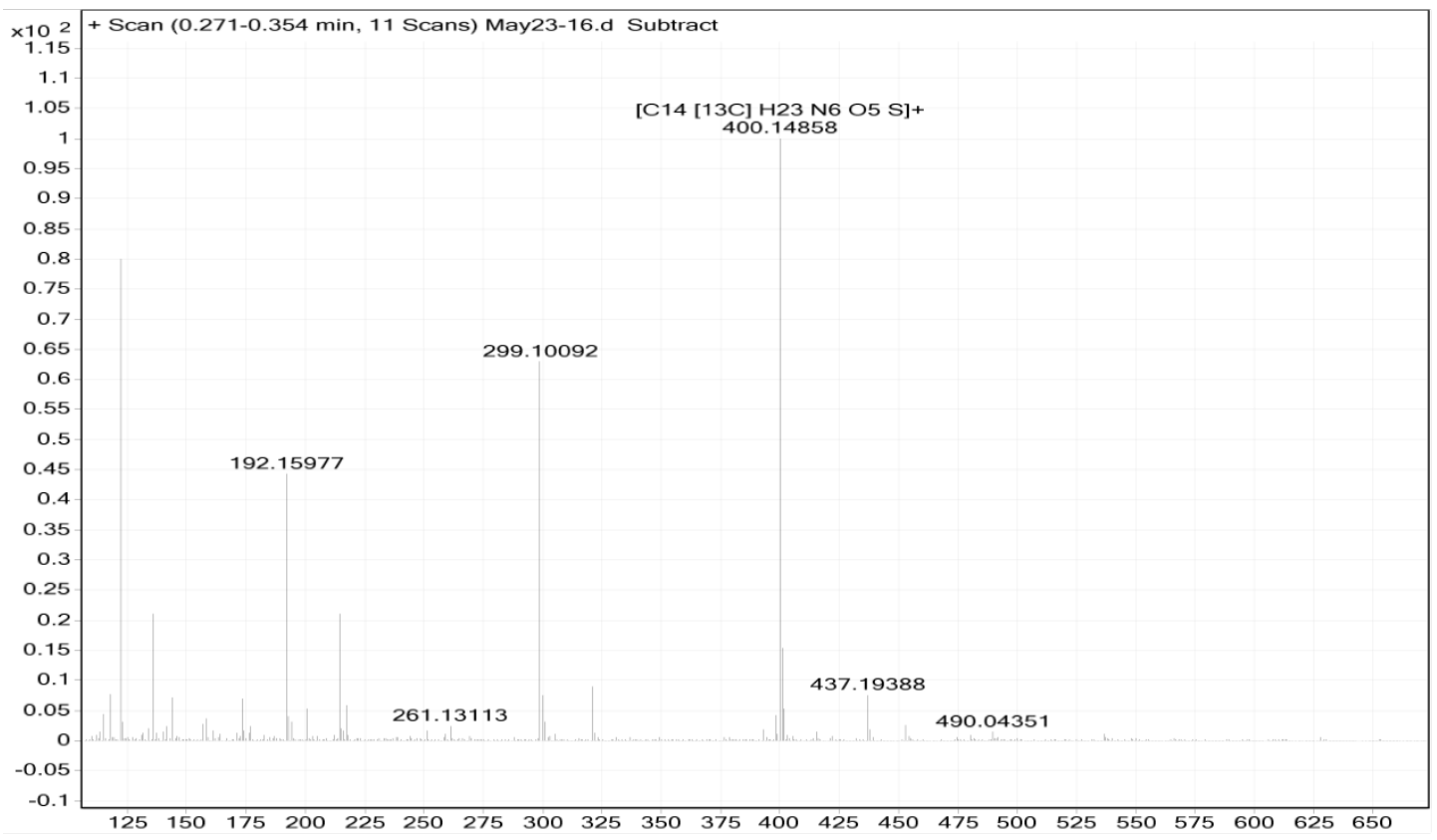

Figure S20. MS of $\left[5^{\prime}-{ }^{13} \mathrm{C}\right] \mathrm{SAM}$.

$\mathrm{m} / \mathrm{z} \mathrm{M}^{+}$calculated for $\mathrm{C}_{14}{ }^{13} \mathrm{CH}_{23} \mathrm{~N}_{6} \mathrm{O}_{5} \mathrm{~S}^{+} 400.1484$; found 400.1486 . 


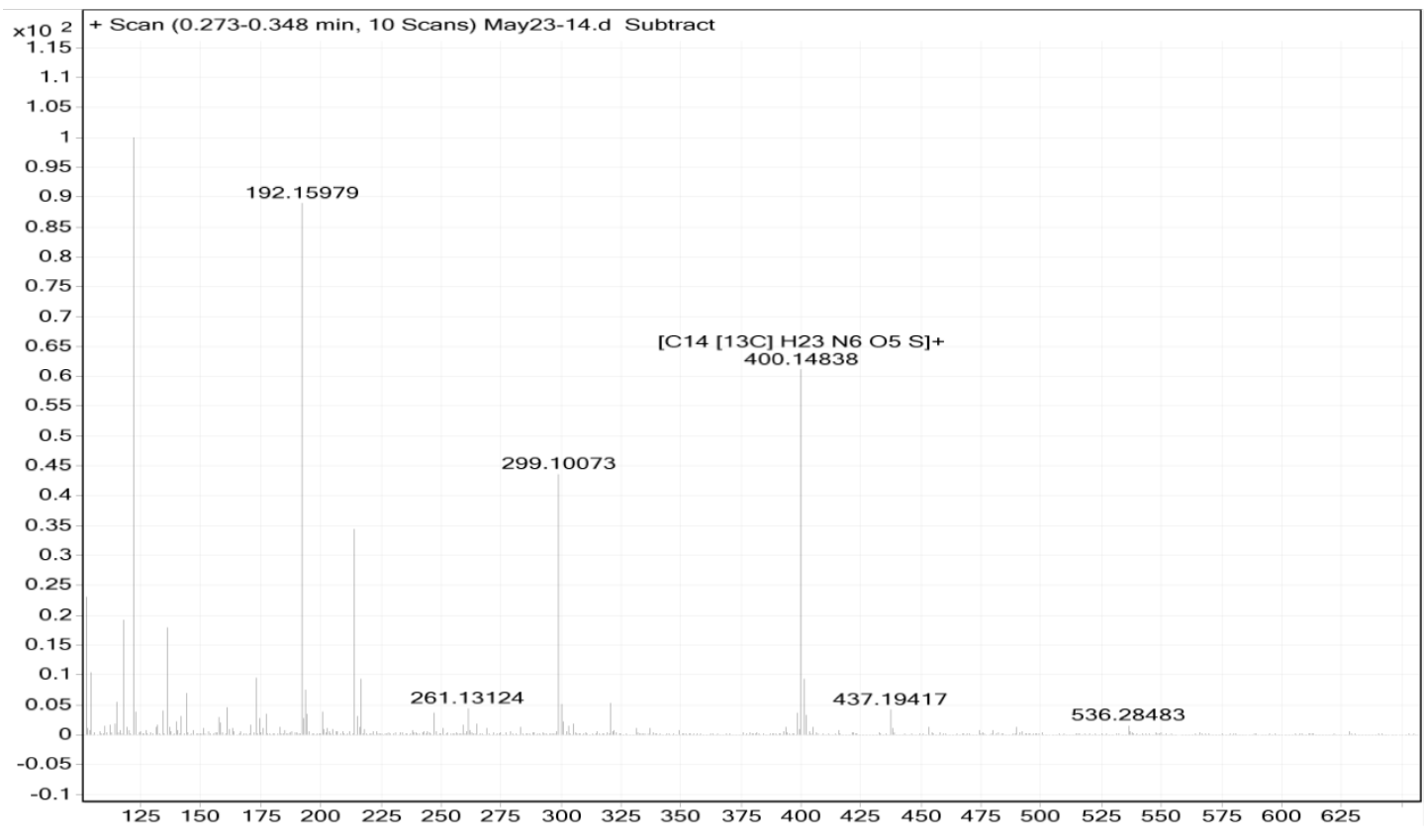

Figure S21. MS of $\left[4^{\prime}-{ }^{13} \mathrm{C}\right] \mathrm{SAM}$.

$\mathrm{m} / \mathrm{z} \mathrm{M}^{+}$calculated for $\mathrm{C}_{14}{ }^{13} \mathrm{CH}_{23} \mathrm{~N}_{6} \mathrm{O}_{5} \mathrm{~S}^{+} 400.1484$; found 400.1484 . 


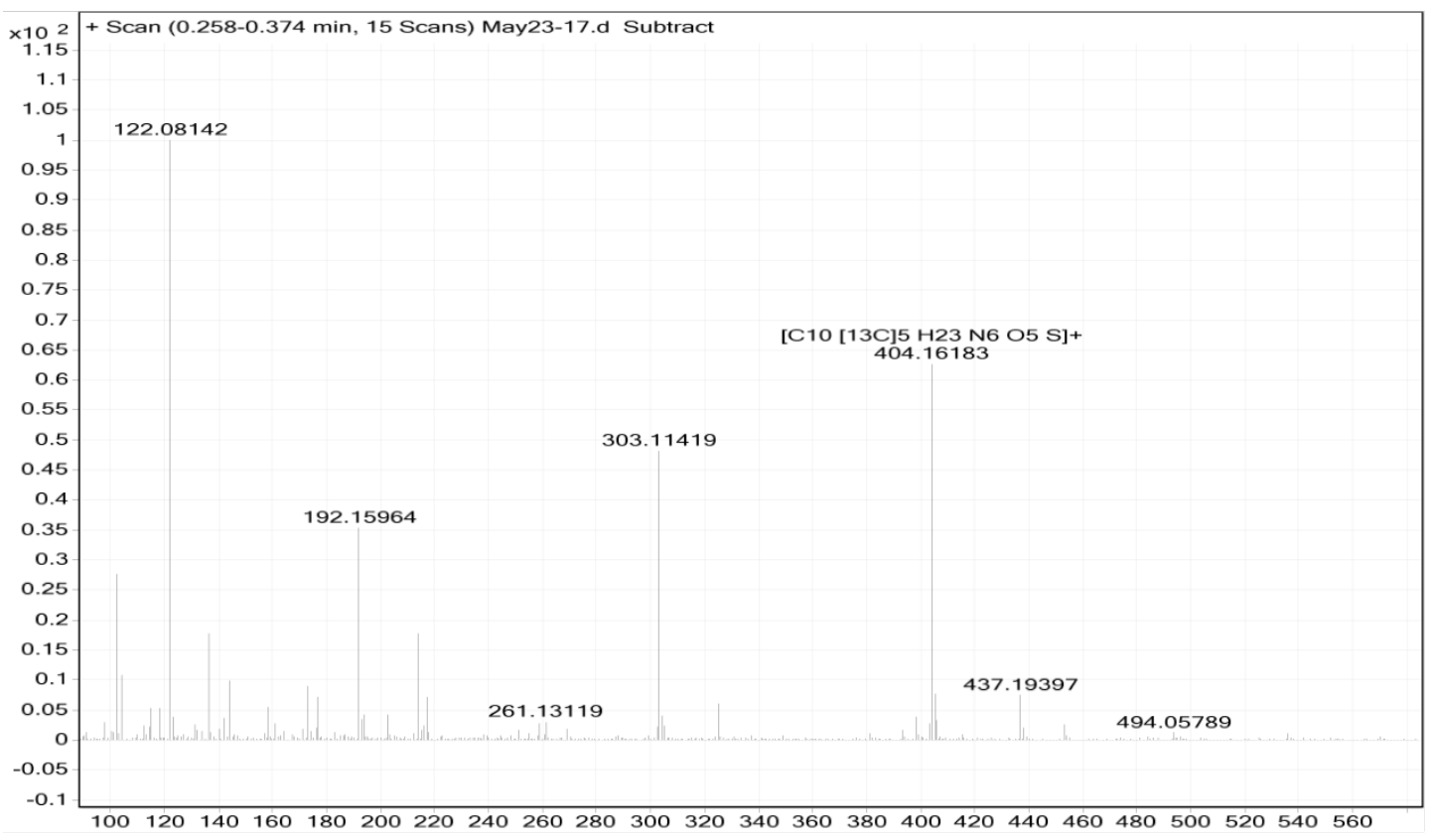

Figure S22. MS of [ribose- ${ }^{13} \mathrm{C}_{5}$ ]SAM.

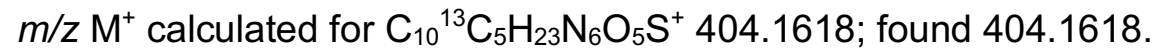




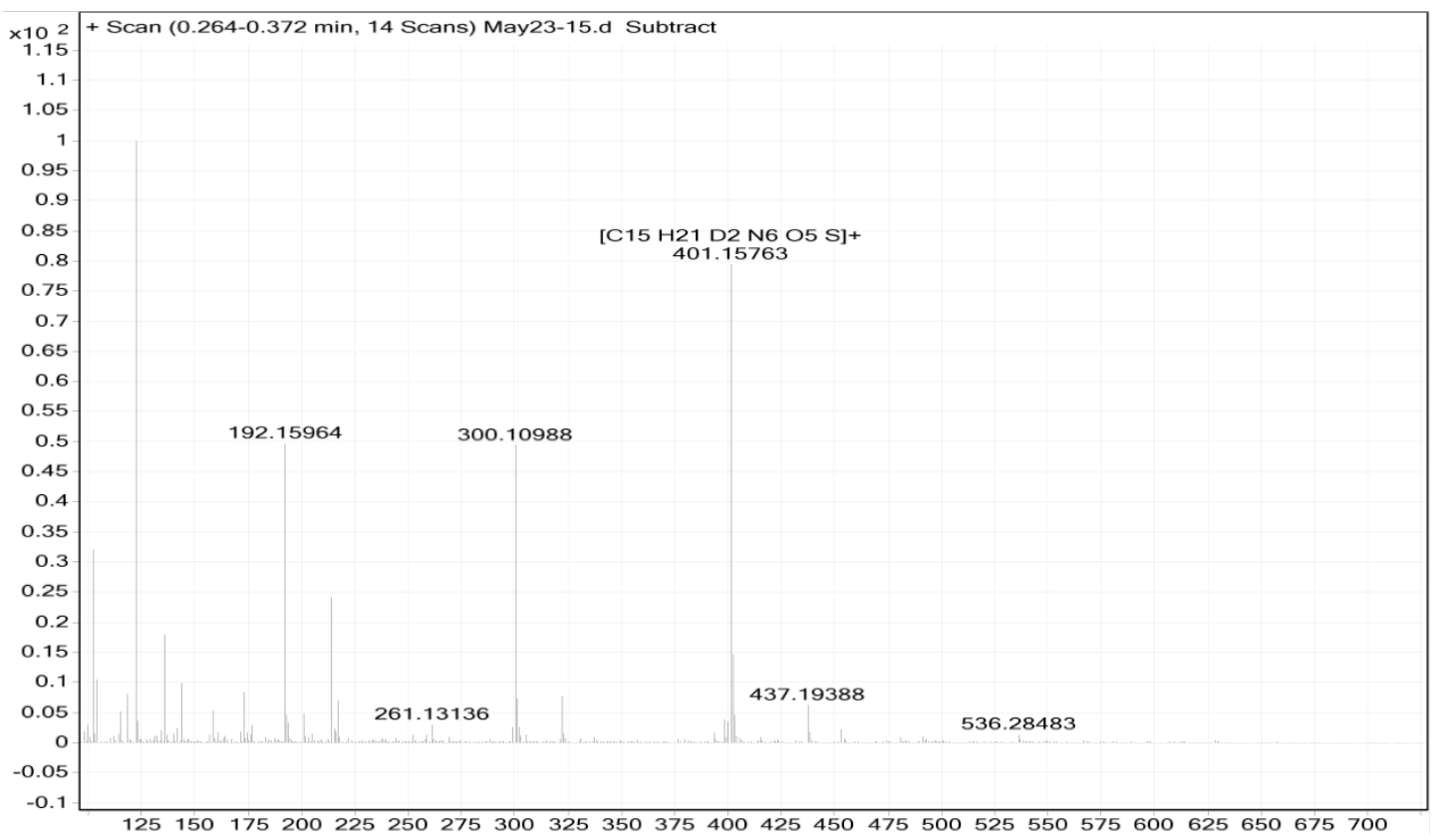

Figure S23. MS of $\left[5^{\prime}-{ }^{2} \mathrm{H}_{2}\right]$ SAM.

$\mathrm{m} / \mathrm{z} \mathrm{M}^{+}$calculated for $\mathrm{C}_{15} \mathrm{H}_{21}{ }^{2} \mathrm{H}_{2} \mathrm{~N}_{6} \mathrm{O}_{5} \mathrm{~S}^{+}$401.1576; found 401.1576 . 


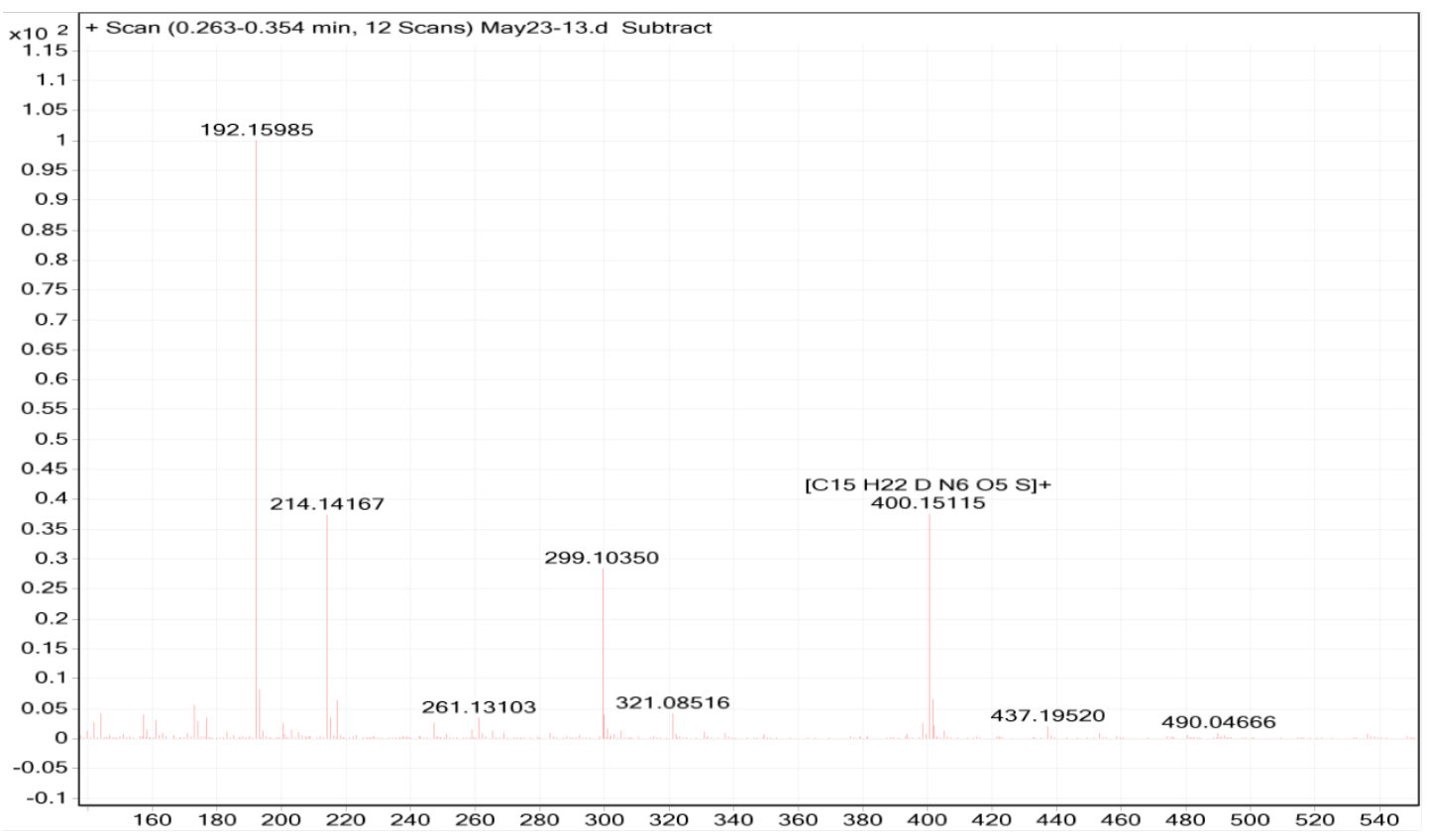

Figure S24. MS of $\left[4^{\prime}{ }^{2} \mathrm{H}\right] \mathrm{SAM}$.

$\mathrm{m} / \mathrm{z} \mathrm{M}^{+}$calculated for $\mathrm{C}_{15} \mathrm{H}_{22}{ }^{2} \mathrm{HN}_{6} \mathrm{O}_{5} \mathrm{~S}^{+} 400.1514$; found 400.1512 . 


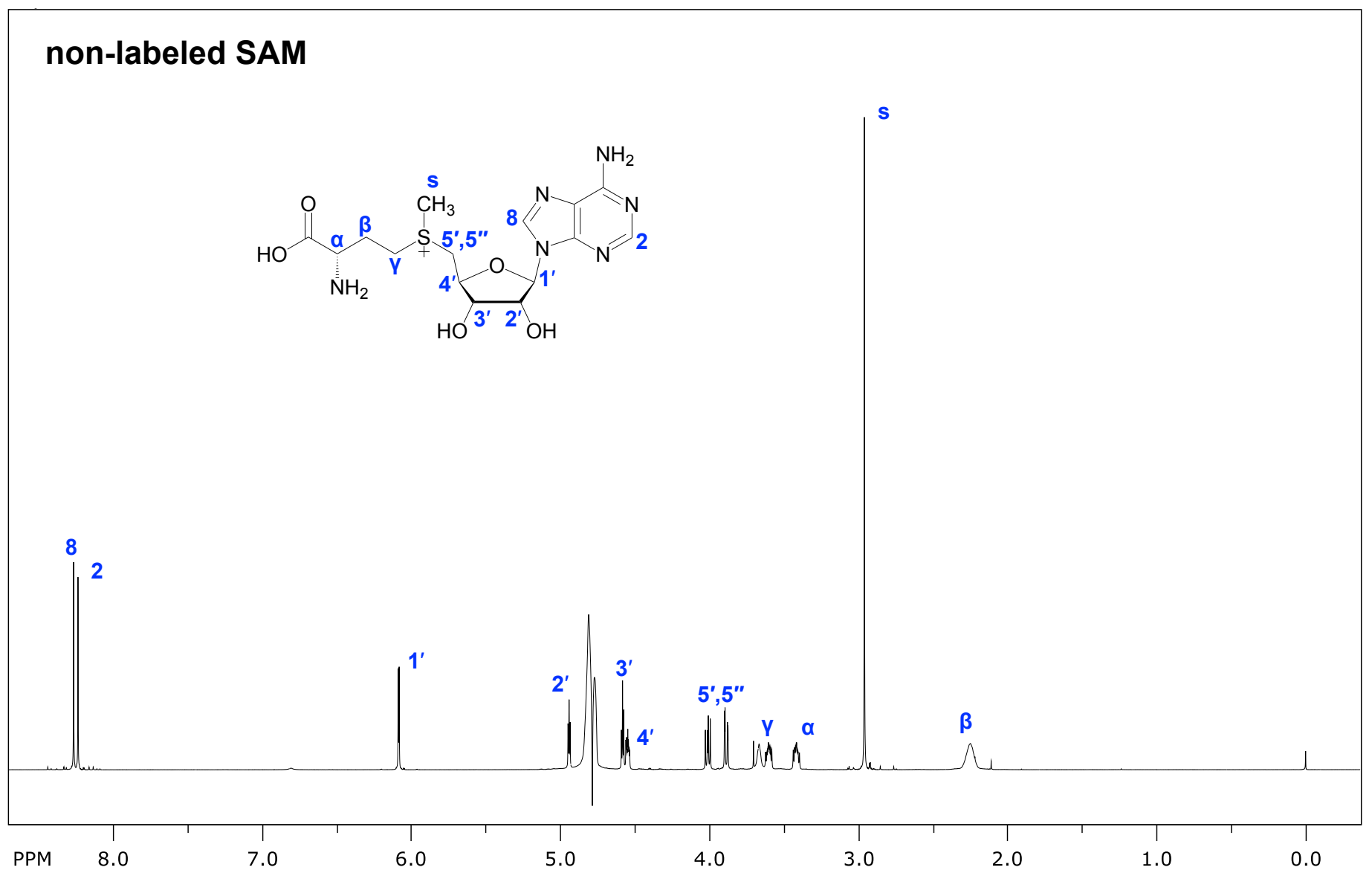

Figure S25. ${ }^{1} \mathrm{H}$ NMR of enzymatically prepared non-labeled SAM.

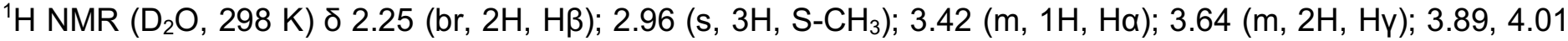
(m, 2H, H5', 5"); 4.55 (m, 1H, H4'); 4.58 (t, 1H, H3'); 4.94 (t, 1H, H2'); 6.09 (d, 1H, H1'); 8.24 (s, $1 \mathrm{H}, \mathrm{H} 2) ; 8.27$ (s, $1 \mathrm{H}, \mathrm{H} 8)$. 


\section{$\left[5^{\prime}-{ }^{13} \mathrm{C}\right]$ SAM}
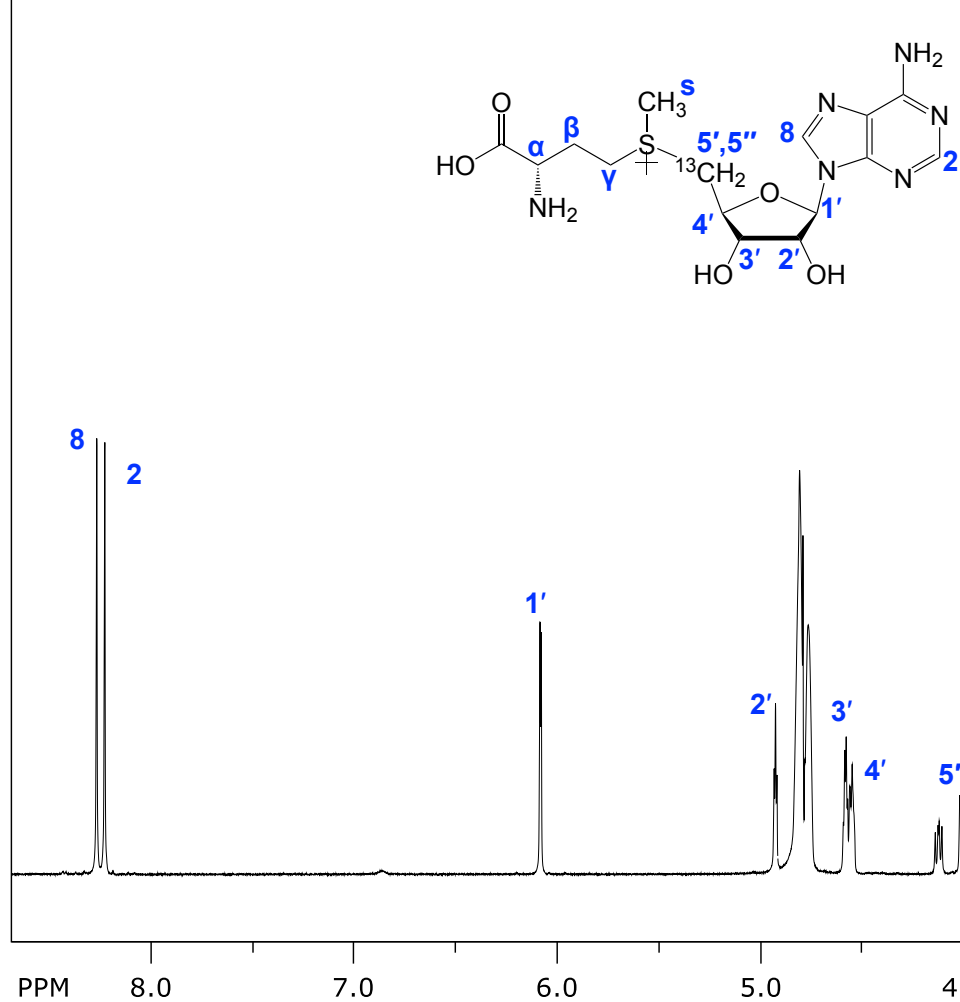

PPM

7.0
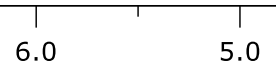

2.0

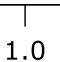

Figure S26. ${ }^{1} \mathrm{H}$ NMR of $\left[5^{\prime}-{ }^{13} \mathrm{C}\right] \mathrm{SAM}$.

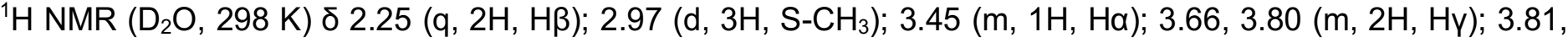
3.91, 4.01, 4.12 (m, 2H, H5', 5", $\left.{ }^{1} \mathrm{~J}_{\mathrm{H}-13 \mathrm{C}}=144 \mathrm{~Hz}\right) ; 4.57$ (m, 2H, H3', 4'); 4.93 (t, 1H, H2'); 6.08 (d, 1H, H1'); 8.23 (s, $1 \mathrm{H}, \mathrm{H} 2) ; 8.27(\mathrm{~s}, 1 \mathrm{H}, \mathrm{H} 8)$. 


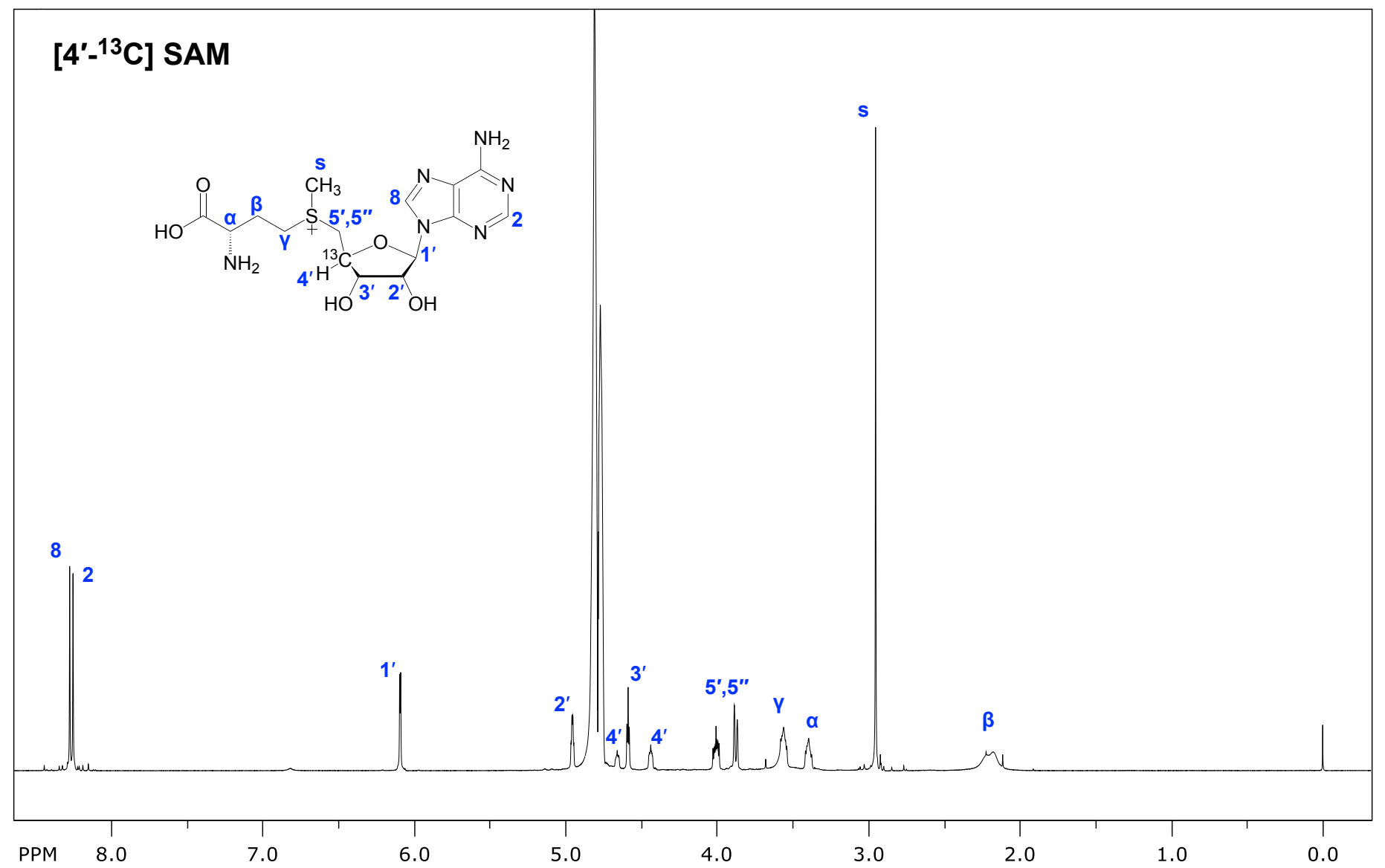

Figure S27. ${ }^{1} \mathrm{H}$ NMR of $\left[4{ }^{-13} \mathrm{C}\right] \mathrm{SAM}$.

${ }^{1} \mathrm{H}$ NMR $\left(\mathrm{D}_{2} \mathrm{O}, 298 \mathrm{~K}\right) \delta 2.18(\mathrm{br}, 2 \mathrm{H}, \mathrm{H} \beta) ; 2.95\left(\mathrm{~s}, 3 \mathrm{H}, \mathrm{S}-\mathrm{CH}_{3}\right) ; 3.40(\mathrm{br}, 1 \mathrm{H}, \mathrm{H \alpha}) ; 3.56(\mathrm{br}, 2 \mathrm{H}, \mathrm{Hr}) ; 3.88,4.01$ (m, 2H, H5', 5"); 4.44, $4.66\left(\mathrm{~m}, 1 \mathrm{H}, \mathrm{H} 4^{\prime},{ }^{1} \mathrm{~J}_{\mathrm{H}-13 \mathrm{C}}=154 \mathrm{~Hz}\right) ; 4.59$ (t, 1H, H3'); 4.96 (q, 1H, H2'); $6.10\left(\mathrm{~d}, 1 \mathrm{H}, \mathrm{H} 1^{\prime}\right)$; $8.26(\mathrm{~s}, 1 \mathrm{H}, \mathrm{H} 2) ; 8.28(\mathrm{~s}, 1 \mathrm{H}, \mathrm{H} 8)$. 


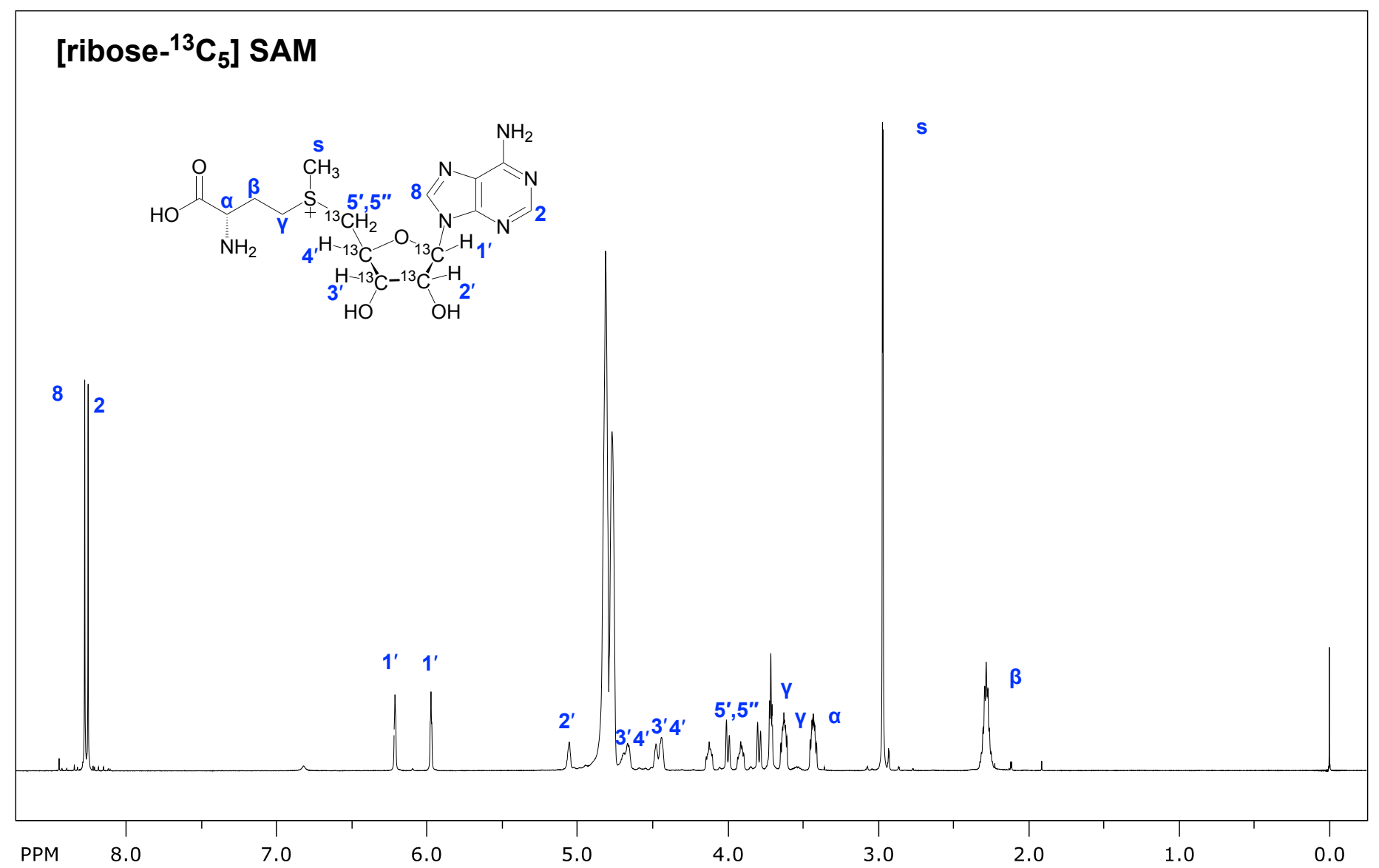

Figure S28. ${ }^{1} \mathrm{H}$ NMR of [ribose $\left.-{ }^{13} \mathrm{C}_{5}\right] \mathrm{SAM}$.

${ }^{1} \mathrm{H}$ NMR ( $\left.\mathrm{D}_{2} \mathrm{O}, 298 \mathrm{~K}\right) \delta 2.28(\mathrm{~m}, 2 \mathrm{H}, \mathrm{H} \beta) ; 2.97\left(\mathrm{~d}, 3 \mathrm{H}, \mathrm{S}-\mathrm{CH}_{3}\right) ; 3.43(\mathrm{~m}, 1 \mathrm{H}, \mathrm{H \alpha}) ; 3.63,3.71(\mathrm{~m}, 2 \mathrm{H}, \mathrm{H \gamma}) ; 3.79$, 3.91, 4.00, $4.12\left(\mathrm{~m}, 2 \mathrm{H}, \mathrm{H} 5\right.$ ', 5", $\left.{ }^{1} \mathrm{~J}_{\mathrm{H}-13 \mathrm{C}}=147 \mathrm{~Hz}\right) ; 4.48,4.70\left(\mathrm{~m}, 1 \mathrm{H}, \mathrm{H} 3^{\prime},{ }^{1} \mathrm{~J}_{\mathrm{H}-13 \mathrm{C}}=154 \mathrm{~Hz}\right) ; 4.44,4.66(\mathrm{~m}, 1 \mathrm{H}$, $\left.\mathrm{H} 4{ }^{\prime},{ }^{1} \mathrm{~J}_{\mathrm{H}-13 \mathrm{C}}=154 \mathrm{~Hz}\right) ; 5.05\left(\mathrm{~m}\right.$, partially buried in $\mathrm{H}_{2} \mathrm{O}$ signal, $\left.\mathrm{H} 2^{\prime}\right) ; 5.97,6.21\left(\mathrm{~m}, 1 \mathrm{H}, \mathrm{H} 1^{\prime},{ }^{1} \mathrm{~J}_{\mathrm{H}-13 \mathrm{C}}=168 \mathrm{~Hz}\right) ; 8.25$ (s, 1H, H2); $8.28(\mathrm{~s}, 1 \mathrm{H}, \mathrm{H} 8)$. 


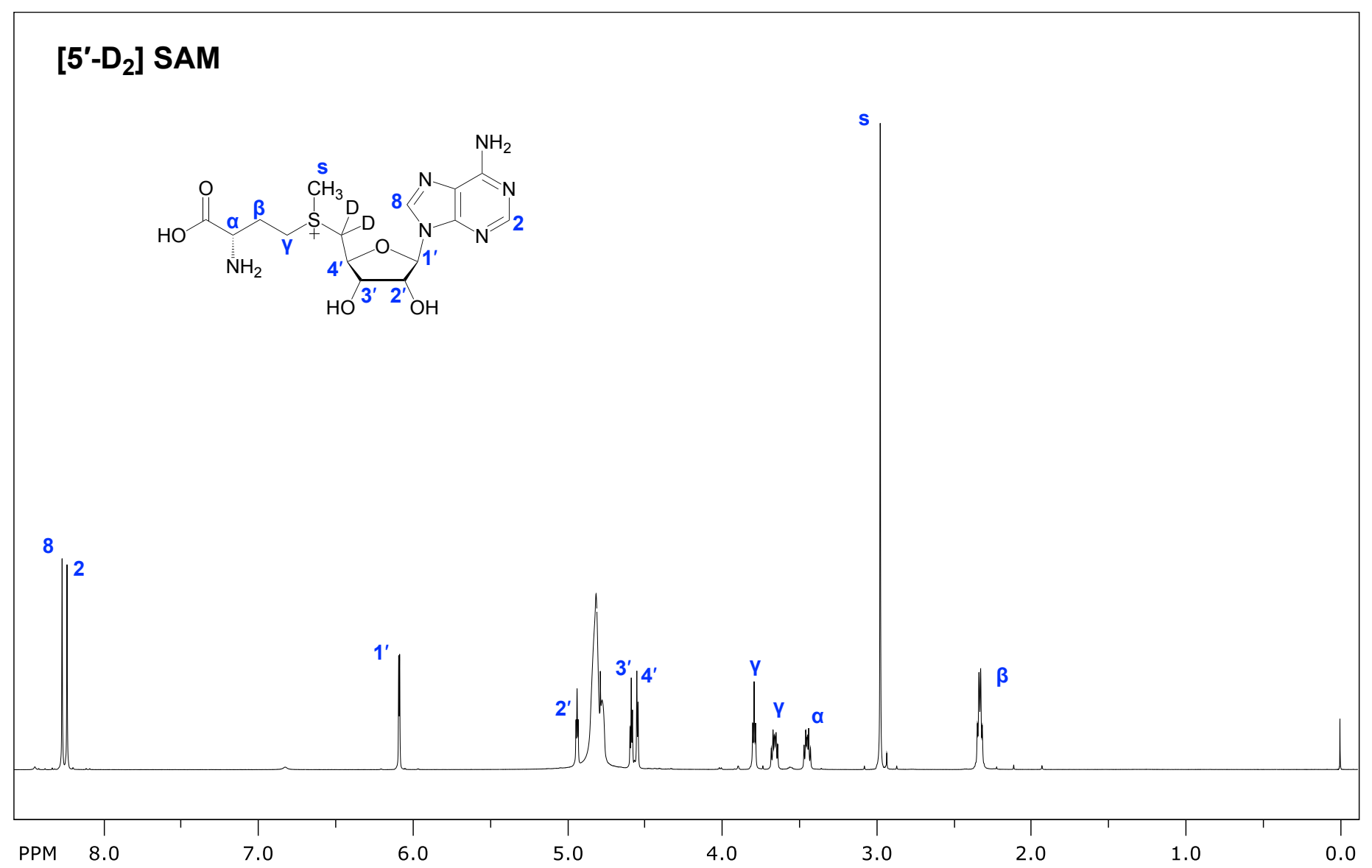

Figure S29. ${ }^{1} \mathrm{H}$ NMR of $\left[5^{2}-{ }^{2} \mathrm{H}_{2}\right] \mathrm{SAM}$.

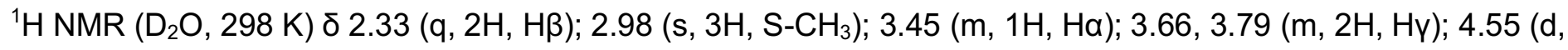
$\left.1 \mathrm{H}, \mathrm{H} 4^{\prime}\right) ; 4.59\left(\mathrm{t}, 1 \mathrm{H}, \mathrm{H} 3^{\prime}\right) ; 4.94$ (t, 1H, H2'); 6.09 (d, 1H, H1'); 8.24 (s, 1H, H2); 8.27 (s, 1H, H8). 


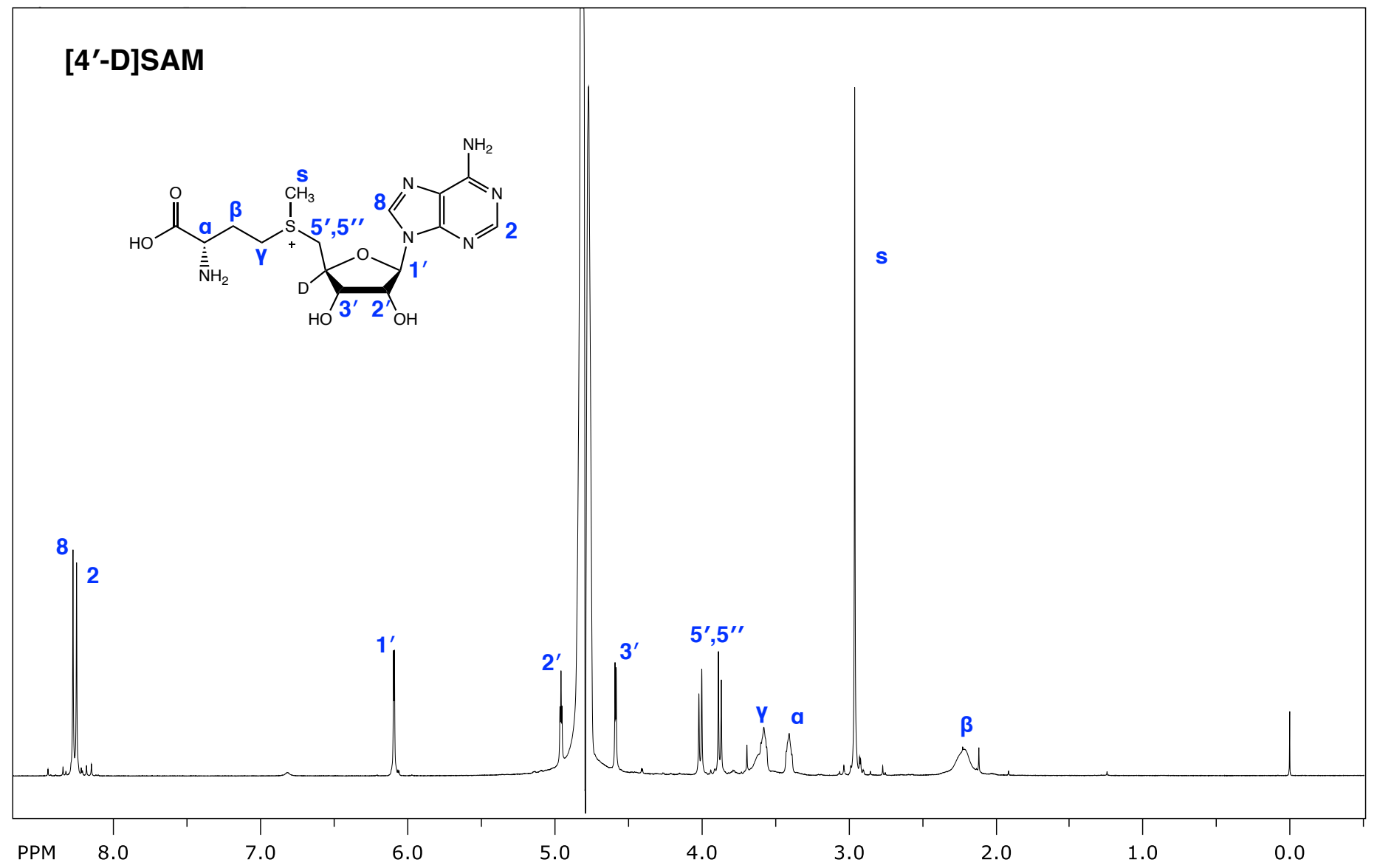

Figure S30. ${ }^{1} \mathrm{H}$ NMR of $\left[4^{\prime}-{ }^{2} \mathrm{H}\right] \mathrm{SAM}$.

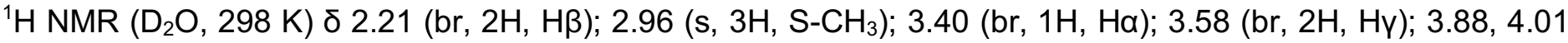
(d, d, 2H, H5', 5"); 4.59 (d, 1H, H3'); 4.96 (t, 1H, H2'); 6.09 (d, 1H, H1'); 8.25 (s, 1H, H2); 8.28 (s, 1H, H8). 


\section{References}

1. Hänzelmann, P.; Hernandez, H. L.; Menzel, C.; Garcia-Serres, R.; Huynh, B. H.; Johnson, M. K.; Mendel, R. R.; Schindelin, H., Characterization of MOCS1A, an oxygen-sensitive iron-sulfur protein involved in human molybdenum cofactor biosynthesis. J Biol Chem 2004, 279 (33), 34721-34732.

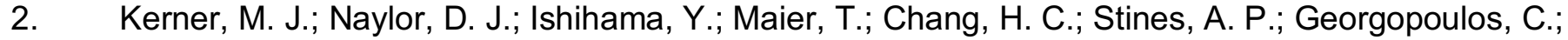
Frishman, D.; Hayer-Hartl, M.; Mann, M.; Hartl, F. U., Proteome-wide analysis of chaperonin-dependent protein folding in Escherichia coli. Cell 2005, 122 (2), 209-220.

3. Iwig, D. F.; Booker, S. J., Insight into the Polar Reactivity of the Onium Chalcogen Analogues of SAdenosyl-I-methionine. Biochemistry 2004, 43 (42), 13496-13509.

4. De León, P.; Marco, S.; Isiegas, C.; Marina, A.; Carrascosa, J. L.; Mellado, R. P., Streptomyces lividans groES, groEL1 and groEL2 genes. Microbiology 1997, 143 (11), 3563-3571.

5. $\quad$ Tolbert, T. J.; Williamson, J. R., Preparation of specifically deuterated RNA for NMR studies using a combination of chemical and enzymatic synthesis. J Am Chem Soc 1996, 118 (34), 7929-7940.

6. $\quad$ Schultheisz, H. L.; Szymczyna, B. R.; Scott, L. G.; Williamson, J. R., Pathway engineered enzymatic de novo purine nucleotide synthesis. ACS chemical biology 2008, 3 (8), 499-511.

7. $\quad$ Griller, D.; Ingold, K. U., Free-radical clocks. Accounts of Chemical Research 1980, 13 (9), $317-323$.

8. Johnston, L. J.; Lusztyk, J.; Wayner, D. D. M.; Abeywickreyma, A. N.; Beckwith, A. L. J.; Scaiano, J. C.; Ingold, K. U., Absolute rate constants for reaction of phenyl, 2, 2-dimethylvinyl, cyclopropyl, and neopentyl radicals with tri-n-butylstannane. Comparison of the radical trapping abilities of tri-n-butylstannane and germane. J Am Chem Soc 1985, 107 (15), 4594-4596.

9. Beckwith, A. L.; Schiesser, C. H., A force-field study of alkenyl radical ring closure. Tetrahedron letters 1985, 26 (3), 373-376.

10. Chatgilialoglu, C.; Guerra, M.; Mulazzani, Q. G., Model studies of DNA C5' radicals. Selective generation and reactivity of 2'-deoxyadenosin-5'-yl radical. J Am Chem Soc 2003, 125 (13), 3839-3848.

11. Lilla, E. A.; Yokoyama, K., Carbon extension in peptidylnucleoside biosynthesis by radical SAM enzymes. Nature chemical biology 2016, 12 (11), 905-907.

12. Baraniak, J.; Moss, M. L.; Frey, P. A., Lysine 2, 3-aminomutase. Support for a mechanism of hydrogen transfer involving S-adenosylmethionine. J Biol Chem 1989, 264 (3), 1357-1360.

13. Yokoyama, K.; Ohmori, D.; Kudo, F.; Eguchi, T., Mechanistic study on the reaction of a radical SAM dehydrogenase BtrN by electron paramagnetic resonance spectroscopy. Biochemistry 2008, 47 (34), 8950-60. 14. Duffus, B. R.; Ghose, S.; Peters, J. W.; Broderick, J. B., Reversible H Atom Abstraction Catalyzed by the Radical S-Adenosylmethionine Enzyme HydG. J Am Chem Soc 2014, 136 (38), 13086-13089.

15. Hover, B. M.; Loksztejn, A.; Ribeiro, A. A.; Yokoyama, K., Identification of a cyclic nucleotide as a cryptic intermediate in molybdenum cofactor biosynthesis. J Am Chem Soc 2013, 135 (18), 7019-32. 